\title{
Band Anticrossing in Dilute Nitrides
}

\author{
W. Shan ${ }^{1}$, K.M. Yu ${ }^{1}$, W. Walukiewicz ${ }^{1}$, J. Wu ${ }^{1}$, J.W. Ager III $^{1}$, and E.E. Haller ${ }^{1,2}$ \\ 1. Materials Sciences Division, Lawrence Berkeley National Laboratory, Berkeley, CA 94720 \\ 2. Department of Materials Science and Engineering, University of California, Berkeley, CA
} 94720

\begin{abstract}
Alloying III-V compounds with small amounts of nitrogen leads to dramatic reduction of the fundamental band-gap energy in the resulting dilute nitride alloys. The effect originates from an anti-crossing interaction between the extended conduction-band states and localized $\mathrm{N}$ states. The interaction splits the conduction band into two nonparabolic subbands. The downward shift of the lower conduction subband edge is responsible for the $\mathrm{N}$-induced reduction of the fundamental band-gap energy. The changes in the conduction band structure result in significant increase in electron effective mass and decrease in the electron mobility, and lead to a large enhance of the maximum doping level in GaInNAs doped with group VI donors. In addition, a striking asymmetry in the electrical activation of group IV and group VI donors can be attributed to mutual passivation process through formation of the nearest neighbor group-IV donor nitrogen pairs.
\end{abstract}

\section{Introduction}

Dilute nitrides have recently attracted considerable attention. It has been found that the substitution of the group $\mathrm{V}$ anions in conventional III-V compounds with small amounts of nitrogen leads to dramatic changes of the electronic properties. These include a reduction of the fundamental band-gap energy, ${ }^{1,2}$ a significant increase in electron effective mass and a decrease in electron mobility. ${ }^{3-5}$ Furthermore, a new optical transition $\left(E_{+}\right)$above the fundamental band 
gap energy has been observed. ${ }^{6,7}$ As one quantitative example, the incorporation of only one percent of nitrogen into GaAs induces a strikingly large reduction of $0.18 \mathrm{eV}$ in the fundamental band-gap energy. ${ }^{8}$ This reduction is much larger than the changes observed when alloying different III-V compound semiconductors at its percent level.

It is now generally accepted that the unexpectedly strong effect of $\mathrm{N}$ on the band gap is related to the fact that replacement of atoms such as As with the much smaller and more electronegative $\mathrm{N}$ atom leads to a large, local perturbation of the crystal lattice potential. Extensive experimental and theoretical studies over the past decade have led to several proposals aimed at understanding of the origin of the large band-gap. ${ }^{9-26}$ In this article, we show that the effect of nitrogen on the electronic band structure of dilute nitrides can be consistently described in terms of an anti-crossing interaction between localized nitrogen states and the extended conduction-band states of the semiconductor matrix. ${ }^{6,27}$ The interaction leads to a significant modification of the band structure of the dilute III-N-V alloys. All the experimentally observed dramatic changes of the electrical and optical properties that have been observed experimentally can be fully explained by this interaction.

\section{Band anticrossing model}

It is well known that an isolated $\mathrm{N}$ atom introduces a localized state with energy level $E_{N}$ in conventional III-V materials. In most cases, this level is located very close to the conduction band edge. It lies at about $0.25 \mathrm{eV}$ above the conduction band edge in GaAs and less than $0.1 \mathrm{eV}$ below the conduction band edge in GaP. The existence of such states has been predicted by theoretical calculations within the tight binding approximation framework, ${ }^{28}$ and confirmed by

experimental measurements under hydrostatic pressure. ${ }^{29,30}$ As expected for a localized state, a much weaker pressure dependence of the $\mathrm{N}$ energy level was observed in GaAs compared to the 
conduction-band edge. The level was also found to move into the band gap when GaAs is alloyed with AlAs. ${ }^{31}$ The highly localized nature of the $\mathrm{N}$ states suggests that there is only weak hybridization between the orbits of $\mathrm{N}$ atoms and the extended states, $E_{M}(k)$, of the semiconductor matrix. The electronic band structure of the host crystal is not significantly affected by these low nitrogen concentrations. However, alloying a few atomic percentage of nitrogen with III-V compounds drastically modifies the electronic band structure.

In considering the problem of the profound changes in the band structure of the resulting dilute III-N-V nitrides, we assume that $\mathrm{N}$ atoms are randomly distributed over the group $\mathrm{V}$ sites and are only weakly coupled to the extended states of the host semiconductor matrix. The eigenvalue problem can then be written as

$$
\left|\begin{array}{cc}
E_{M}(k)-E(k) & V_{M N} \\
V_{M N} & E_{N}-E(k)
\end{array}\right|=0,
$$

where $E_{M}(k)$ and $E_{N}$ are the energies of the unperturbed conduction band and of the localized states relative to the top of the valence band, respectively. $V_{M N}=\langle k|\mathrm{~V}| \mathrm{N}\rangle$ is the matrix element describing the coupling between N-states and the extended conduction-band states, $\mathrm{V}=\sum_{\mathrm{s}} \mathrm{U}\left(\mathbf{r}-\mathbf{R}_{\mathrm{s}}\right)$, and $\mathrm{U}\left(\mathbf{r}-\mathbf{R}_{\mathbf{s}}\right)$ is the potential introduced by an $\mathrm{N}$ atom on a $\mathbf{R}_{\mathbf{s}}$ site. The solution of Eq.(1) takes the form

$$
E_{ \pm}(k)=\frac{1}{2}\left\{\left(E_{M}(k)+E_{N}\right) \pm \sqrt{\left(E_{M}(k)-E_{N}\right)^{2}+4{V_{M N}^{2}}^{2}}\right\} .
$$

The squared matrix element coupling $k$ and $\mathrm{N}$ states, is given by ${ }^{27}$

$$
\begin{aligned}
\left|V_{M N}\right|^{2} & =\langle k|\mathrm{~V}| \mathrm{N}\rangle\langle\mathrm{N}|\mathrm{V}| k\rangle \\
& =\Sigma_{\mathrm{s}} \Sigma_{\mathrm{s}^{\prime}} \iint \mathrm{V}^{-2} \mathrm{dr} \mathbf{r} \mathbf{r}^{\prime} \mathrm{e}^{\mathrm{ikr}} \mathrm{U}^{*}\left(\mathbf{r}-\mathbf{R}_{\mathbf{s}}\right) \Psi^{*}{ }_{\mathrm{N}}\left(\mathbf{r}-\mathbf{R}_{\mathbf{s}}\right) \mathrm{U}\left(\mathbf{r}^{\prime}-\mathbf{R}_{\mathbf{s}^{\prime}}\right) \Psi_{\mathrm{N}}\left(\mathbf{r}^{\prime}-\mathbf{R}_{\mathbf{s}}\right) \mathrm{e}^{-\mathrm{ikr}} .
\end{aligned}
$$


$\Psi_{\mathrm{N}}(\mathbf{r})$ is the wavefunction of $\mathrm{N}$ state localized on the substitutional site. Eq.(3) is valid for low $\mathrm{N}$ concentrations when there is no appreciable overlap between functions $\mathrm{S}\left(\mathbf{r}-\mathbf{R}_{\mathbf{s}}\right)=\mathrm{U}\left(\mathbf{r}-\mathbf{R}_{\mathbf{s}}\right) \Psi_{\mathrm{N}}\left(\mathbf{r}-\mathbf{R}_{\mathbf{s}}\right)$ located on different sites. Using the Fourier transform of the function $\mathrm{S}(\mathbf{r}), \mathrm{V}_{\mathrm{NM}}$ can be written as

$$
\left|V_{M N}\right|^{2}=|\mathrm{S}(\mathrm{k})|^{2}\left\{\Sigma_{\mathrm{s}} \Sigma_{\mathrm{s}^{\prime}} \cdot \exp \left[\mathrm{ik}\left(\mathbf{R}_{\mathbf{s}}-\mathbf{R}_{\mathbf{s}^{\prime}}\right)\right]\right\} .
$$

The double sum in Eq.(4) has to be averaged over all possible $\mathrm{N}$ atom configurations in the host crystal lattice. For a random distribution it equals the total number of substitutional $\mathrm{N}$ atoms which is proportional to the molar fraction of $\mathrm{N}$ in the alloys. Therefore the matrix element can be written as $V_{M N}=C_{M N} x^{1 / 2}$, where $C_{M N}$ is a constant describing the coupling between localized states and the extended states of the semiconductor matrix and $x$ is the alloy composition. The interaction of the conduction-band edge with the dispersionless $\mathrm{N}$ level results in a splitting of the conduction band into two highly nonparabolic subbands, $E_{-}(k)$ and $E_{+}(k)$. The energy positions of the subband edges $E_{-}$and $E_{+}$given by Eq.(2) depend on alloy concentration $x$ and the coupling parameter $C_{M N}$, as well as the location of $E_{N}$ with respect to the conduction band edge $E_{M}$.

Figure 1 shows schematic examples of the calculated band structure based on the BAC model. The interaction between the localized isoelectronic states and the extended conductionband states has a pronounced effect on the dispersion relation of the two conduction subbands $E_{-}$ and $E_{+}$. The effect of the interaction is most pronounced for the states located close to $E_{N}$. If the localized state is located within the conduction band of the matrix, as depicted in Fig.1(a), the conduction-band states at the $E_{-}$edge retain mostly the extended $E_{M}$-like character and those at the $E_{+}$edge have a more localized and $E_{N}$-like character. The lower conduction subband narrows drastically as the energy position of $E_{N}$ level moves down relative to the bottom of the conduction band. Narrowing of the band indicates a gradually increased contribution of the 
localized nature to the lowest subband, leading to a highly nonparabolic dispersion relationship that induces an enhancement of the effective mass and the density of states in the lower subband. If the localized states is located below the conduction-band edge, as illustrated in Fig.1(b), the conduction-subband edges $E_{-}$and $E_{+}$switch their character: the $E_{-}$subband states assume the highly localized nature and $E_{+}$subband states possess the character of extended state.

The electron effective mass as a function of energy can be calculated using the standard definition of the density of states effective mass,

$$
m_{-}^{*}\left(\mathbf{k}_{F}\right)=\hbar^{2}\left|\frac{k}{d E_{-}(\mathbf{k}) / d k}\right|_{k=\mathbf{k}_{F}}=m_{0}^{*} \cdot\left[1+\frac{C_{M N}{ }^{2} x}{\left(E_{N}-E_{-}\left(\mathbf{k}_{F}\right)\right)^{2}}\right]
$$

where $m_{0} *$ is the effective mass of the semiconductor matrix and $E$ is the energy in the lower or upper subband measured from the valence band edge. It is seen from Eq.(5) that the effective mass diverges for the electron energy approaching $E_{N}$. This is a result of the increasing contribution of the localized $\mathrm{N}$ states to the electron states in the lower and upper subbands.

Recent theoretical considerations using the tight binding approximation have provided additional refinements for the BAC model. ${ }^{32,33}$ It has been argued that the conventional $\mathbf{k} \cdot \mathbf{p}$ model must be modified to include two extra spin-degenerate nitrogen states as to use ten bands to describe the electronic band structure of $\mathrm{GaNAs} / \mathrm{GaAs}$ and related heterostructures. In addition, detailed studies on the nearest-neighbor environment of the substitutional $\mathrm{N}$ atoms in GaInNAs have shown that the fundamental band-gap energy in quaternary dilute nitride alloys is fairly sensitive to the local environmental conditions especially in the case of quantum well structures. $^{34,35}$

\section{Experimental Results and Discussion}

\subsection{Samples}


A large variety of dilute III-N-V nitrides including GaNAs, GaInNAs, AlGaNAs, GaNP, and InNP have been extensively studied during the past several years. The majority of the samples used in the studies discussed below were grown by either metalorganic vapor phase epitaxy (MOCVD) with dimethylhydrazine as nitrogen source or gas-source molecular beam epitaxy (MBE) using a RF plasma nitrogen radical beam source. The nitrogen contents in those samples were determined using secondary ion mass spectrometry (SIMS) and indirectly from the change of the lattice constant measured with the (004) reflection in double-crystal x-ray diffraction.

A new method for synthesizing dilute nitrides was developed during the course of the studies. We have found that nitrogen implantation followed by rapid thermal annealing (RTA) is a practical and convenient method for the formation of diluted III-N-V alloys. ${ }^{36,37}$ The fundamental band-gap energy for the ion beam synthesized thin films of $\mathrm{GaN}_{\mathrm{x}} \mathrm{As}_{1-\mathrm{x}}, \operatorname{InN}_{\mathrm{x}} \mathrm{P}_{1-\mathrm{x}}$ and $\mathrm{Al}_{\mathrm{y}} \mathrm{Ga}_{1-\mathrm{y}} \mathrm{N}_{\mathrm{x}} \mathrm{As}_{1-\mathrm{x}}$ after $\mathrm{N}^{+}$implantation into GaAs, InP and $\mathrm{Al}_{\mathrm{y}} \mathrm{Ga}_{1-\mathrm{y}} \mathrm{As}$ was found to decrease with increasing $\mathrm{N}$ implantation dose in a manner similar to that observed in epitaxially grown thin films. In $\mathrm{GaN}_{\mathrm{x}} \mathrm{As}_{1-\mathrm{x}}$ the highest value of $\mathrm{x}$ achieved using $\mathrm{N}^{+}$-implantation and conventional RTA technique was 0.006 ; this corresponds to a $\mathrm{N}$ activation efficiency of $\sim 15 \%$. In the course of optimizing the annealing conditions in these studies, it was found that, in GaNAs formed in this way, the substitutional $\mathrm{N}_{\mathrm{As}}$ is thermally unstable at temperatures higher than $850^{\circ} \mathrm{C}$ and will precipitate to form N-related voids. ${ }^{38}$

Most recently, we have shown that pulsed laser melting (PLM) of N-implanted III-Vs dramatically improves the incorporation of $\mathrm{N}$ on the group-V element site. ${ }^{39,40}$ In PLM, the near surface absorption of a single intense laser pulse instantaneously melts the implant-damaged or amorphized layer. This is followed immediately by rapid epitaxial regrowth from the liquid. 
Epitaxy is seeded at the solid-liquid interface by the crystalline bulk in a manner very similar to liquid phase epitaxy (LPE) but with the whole process occurring on a much shorter time scale, typically between $10^{-8}-10^{-6}$ second. ${ }^{41,42}$ Figure 2 shows a series of photoreflectance (PR) spectra from GaAs implanted with increasing amounts of N processed by PLM with an energy fluence of $0.34 \mathrm{~J} / \mathrm{cm}^{2}$ and subsequently by RTA at $950^{\circ} \mathrm{C}$ for ten seconds. Such PLM-RTA postimplantation treatments represent the "optimum" process conditions found to date and the samples so formed have clear, sharp optical transitions. The amount of $\mathrm{N}$ incorporated in the As sublattice ("active" $\mathrm{N}$ ) for the $\mathrm{GaN}_{\mathrm{x}} \mathrm{As}_{1-\mathrm{x}}$ layers formed by this method can be estimated using the BAC model and is $\sim 40-60 \%$ of the implanted value. This is over five times higher than that observed in samples processed by RTA only. ${ }^{37}$ Such a drastic improvement can be attributed to the extremely short melt duration $\left(\sim 2 \times 10^{-7} \mathrm{~s}\right)$ and re-growth process that promotes $\mathrm{N}$ substitution in the As site and inhibits the formation of nitrogen related voids. ${ }^{38}$ In addition to the enhanced $\mathrm{N}$ incorporation, the dilute nitride layers synthesized by $\mathrm{N}^{+}$-implantation followed by PLM-RTA were also found to be thermally stable up to annealing temperature $>950^{\circ} \mathrm{C}$. This improved sample synthesis technique provides a convenient and reliable method, in addition to conventional epitaxial growth techniques, ${ }^{2,4,12}$ for preparing large variety of dilute nitride samples.

\subsection{Direct evidence of band splitting and related anticrossing charateristics}

The key result of the BAC model is that it predicts a splitting of the conduction band into two nonparabolic subbands with energy minima at $E_{-}$and $E_{+}$. The conduction band splitting has been unambiguously observed in $\mathrm{GaN}_{\mathrm{x}} \mathrm{As}_{1-\mathrm{x}}$ and $\mathrm{Ga}_{1-\mathrm{y}} \mathrm{In}_{\mathrm{y}} \mathrm{N}_{\mathrm{x}} \mathrm{As}_{1-\mathrm{x}}$ using photomodulation spectroscopy. ${ }^{6,43}$ Shown in Fig. 3 are PR spectra recorded with MOCVD-grown $\mathrm{GaN}_{\mathrm{x}} \mathrm{As}_{1-\mathrm{x}}$ samples. The PR curve of GaAs $(x=0)$ exhibits two sharp derivative-like spectral features 
corresponding to the transition from the top of valence band to the bottom of the conduction band ( $\mathrm{E}_{0}$ transition), and the transition between the spin-orbit split-off band and the conductionband minimum $\left(\mathrm{E}_{0}+\Delta_{0}\right.$ transition). For $\mathrm{N}$ containing samples, in addition to the PR spectral features related to the transition across the fundamental band gap (E_ transition) and the transition from the top of the spin-orbit split-off valence band to the bottom of the conduction band ( $\mathrm{E}_{-}+\Delta_{0}$ transition), an extra feature $\left(\mathrm{E}_{+}\right)$appears at higher energies in the PR spectra. With increasing $\mathrm{N}$ concentration, the $\mathrm{E}_{-}$and $\mathrm{E}_{-}+\Delta_{0}$ transitions shift to lower energy, as commonly observed in $\mathrm{GaN}_{\mathrm{x}} \mathrm{As}_{1-\mathrm{x}}$, and the $\mathrm{E}_{+}$transition moves in the opposite direction toward higher energy, indicating that the $E_{-}$subband edge shifts downward and the $E_{+}$subband edge moves to the other direction with respect to the top of the valence band.

The predictions of the BAC model are further verified by the measurement of the $\mathrm{E}_{-}$and $\mathrm{E}_{+}$transitions. Application of hydrostatic pressure shifts the bottom of the conduction band above the localized $\mathrm{N}$ level, gradually changing the character of the $E_{-}$-subband edge from extended $E_{M}$-like to localized $E_{N}$-like, and the character of the $E_{+}$-subband edge from the localized-like to extended-like. Such a transformation can be schematically visualized by Fig.1. The dispersion relations of the $E_{-}(k)$ and $E_{+}(k)$ conduction subbands shown in Fig.1(a) represent the case at low pressures where the bottom of the conduction band of the host matrix $\left(E_{M}\right)$ is below the $E_{N}$ level. Fig.1(b) represents the case at high pressures where $E_{M}$ is shifted to above the $E_{N}$ level. The effect of hydrostatic pressure on the optical transitions associated with the $E_{-}$ and $E_{+}$subband edges in a $\mathrm{GaN}_{0.015} \mathrm{As}_{0.985}$ sample and a $\mathrm{Ga}_{0.95} \mathrm{In}_{0.05} \mathrm{~N}_{0.012} \mathrm{As}_{0.988}$ sample is shown in Fig 4. The anti-crossing behavior of two strongly interacting energy levels with distinctly different pressure dependencies is unmistakably observed. The $\mathrm{E}_{-}$transition has a strong dependence at low pressures and gradually saturates at high pressures, whereas the $\mathrm{E}_{+}$transition 
has a weak dependence upon pressure at low pressures and displays a much stronger dependence at high pressures. The solid lines through the experimental data in the figure are the results of calculations using Eq.(2). The best fits to the data yield the energy of the nitrogen state, $E_{N}=E_{V}+1.65 \mathrm{eV}$ for both samples at atmospheric pressure, and it is independent of In concentration. ${ }^{6,43}$ These results prove that the effects of alloying with In on the band gap can be separated from the shifts produced by the interaction with $\mathrm{N}$ states, allowing for an independent determination of $E_{M}$ from a given In concentration in $\mathrm{Ga}_{1-\mathrm{y}} \mathrm{In}_{\mathrm{y}} \mathrm{N}_{\mathrm{x}} \mathrm{As}_{1-\mathrm{x}}$ alloys.

To further verify that the observed $\mathrm{E}_{+}$transition in dilute nitrides results from the Ninduced conduction-band splitting and to clarify the role of the higher conduction-band $\mathrm{L}$ and $\mathrm{X}$ minima on the $\mathrm{E}_{+}$transition, the effect of $\mathrm{N}$ on the band structure of $\mathrm{Al}_{\mathrm{y}} \mathrm{Ga}_{1-\mathrm{y}} \mathrm{As}$ has also been studied. It has been well established that, with increasing $\mathrm{Al}$ concentration, the $\Gamma$ band edge shifts from below to above the $\mathrm{L}$ and $\mathrm{X}$ conduction valleys in $\mathrm{Al}_{\mathrm{y}} \mathrm{Ga}_{1-\mathrm{y}} \mathrm{As}$. This relative energy shift should strongly affect the strength of the interaction between those levels. Energy positions of the experimentally observed $\mathrm{E}_{+}$and $\mathrm{E}_{-}$transitions for $\mathrm{GaN}_{0.0085} \mathrm{As}_{0.9915}$ and four $\mathrm{Ga}_{1-}$ ${ }_{y} \mathrm{Al}_{\mathrm{y}} \mathrm{N}_{\mathrm{x}} \mathrm{As}_{1-\mathrm{x}}$ samples synthesized by $\mathrm{N}^{+}$implantation followed by RTA treatment are shown in Fig. 5. The dependencies of the $\Gamma, \mathrm{L}$ and $\mathrm{X}$ conduction-band minima on the $\mathrm{Al}$ content are also shown in the figure. The inset shows the PR spectra of an as-grown $\mathrm{Al}_{0.35} \mathrm{Ga}_{0.65} \mathrm{As}$ sample and a $\mathrm{N}^{+}$-implanted $\mathrm{Al}_{0.35} \mathrm{Ga}_{0.65} \mathrm{~N}_{\mathrm{x}} \mathrm{As}_{1-\mathrm{x}}$ sample. As shown in the figure, the positions of the $\mathrm{E}_{+}$and $\mathrm{E}_{-}$ transitions can be well explained assuming an anti-crossing interaction between states at the $\Gamma$ minimum and a state $E_{N}$ whose energy depends on the $\mathrm{Al}$ content (y) as $E_{N}=1.65+0.61 \mathrm{y} \mathrm{eV} .^{31}$ The results illustrate clearly that an interaction between the $\mathrm{X}$ and $\Gamma$ minima or the $\mathrm{L}$ and $\Gamma$ minima only due to $\mathrm{N}$-induced symmetry breaking but without taking the $\mathrm{N}$ levels into account, as proposed in Refs.23-26, cannot account for the positions of the experimentally observed $\mathrm{E}_{+}$ 
and $\mathrm{E}_{-}$transitions. There is no correlation between the location of the $\mathrm{X}$ or $\mathrm{L}$ minimum and the $\mathrm{E}_{-}$and $\mathrm{E}_{+}$transition energies. For example, the $\mathrm{L}$ - and $\mathrm{X}$-edges located below the $\Gamma$ edge in $\mathrm{Al}_{\mathrm{y}} \mathrm{Ga}_{1-\mathrm{y}} \mathrm{As}$ with $\mathrm{y}>0.35$, it would not be possible if an interaction between $\Gamma$ and $\mathrm{X}$ or between $\Gamma$ and L could result in the $E_{+}$band edge shifting to an energy position high above the $\Gamma$ edge.

It has to be pointed out that although the theoretically predicted interactions ${ }^{23-26}$ between extended band-edge states do not play any major role in the N-induced modification of the conduction band structure of III-N-V alloys, it is possible that they could be of some significance in those instances where the levels lie close to each other. Such may be the case in GaInNAs at pressures higher than $100 \mathrm{kbar}$ where the $\mathrm{X}$ minimum should become resonant with the $E_{-}$edge. Experimentally, in this case, the E_ transition shifts to a slightly lower energy with increasing pressures (Fig.5). The estimated additional energy shift is of the order of $30 \mathrm{meV}$. This value is approximately one order of magnitude smaller than the energy shift of the $E_{-}$edge at atmospheric pressure resulting from the anticrossing interaction between the $\Gamma$ edge and the localized N-states.

\subsection{Enhancement in maximum free electron concentration}

As has been discussed above, the BAC model not only explains the band gap reduction in dilute III-N-V nitrides but it also predicts that the $\mathrm{N}$-induced modifications of the conduction band will have profound effects on the transport properties of those material systems. ${ }^{27}$ In particular, the downward shift of the conduction band edge and the enhancement of the DOS effective mass will lead to much enhanced maximum free electron concentration $\mathrm{n}_{\max }$.

The maximum achievable electron and/or hole concentration is of great importance in semiconductor devices engineering. A universal rule that governs the maximum free carrier concentration achievable by doping has been developed based on an amphoteric native defect 
model and demonstrated to be valid for a wide variety of semiconductor materials. ${ }^{44,45}$ In that model, the type and concentrations of the defects compensating intentionally introduced dopants depends on the location of the Fermi level relative to a material-independent common energy reference called Fermi level stabilization energy $E_{\mathrm{FS}}$. GaAs is predicted, for example, to exhibit limitations on the maximum free electron concentration. Indeed, the maximum electron concentration $\mathrm{n}_{\max }$ in GaAs achievable under equilibrium conditions has been experimentally confirmed to be limited to about $10^{18}-10^{19} \mathrm{~cm}^{-3} \cdot 46$

Shown in Fig. 6 are the free electron concentrations in Se doped MOCVD-grown $\mathrm{Ga}_{1-}$ ${ }_{3 \mathrm{x}} \mathrm{In}_{3 \mathrm{x}} \mathrm{N}_{\mathrm{x}} \mathrm{As}_{1-\mathrm{x}}$ films with $\mathrm{x}=0$ to 0.033 measured by Hall effect and the electrochemical capacitance-voltage (ECV) technique. ${ }^{47}$ Since the Se atomic concentrations in these films are at least an order of magnitude higher than the free electron concentration (in the range of $2 \sim 7 \times 10^{20} \mathrm{~cm}^{-3}$ ), the measured free electron concentration should be regarded as the maximum achievable free electron concentration, $\mathrm{n}_{\max }$. The result shown in Fig.6 indicates that the $\mathrm{n}_{\max }$ increases strongly with the $\mathrm{N}$ concentration. A maximum value of $7 \times 10^{19} \mathrm{~cm}^{-3}$ was observed for $\mathrm{x}=0.033$. This value is $\sim 20$ times that found in a GaAs film $\left(3.5 \times 10^{18} \mathrm{~cm}^{-3}\right)$ grown under the same conditions. The much-enhanced $n_{\max }$ in $\mathrm{Ga}_{1-3 \mathrm{x}} \operatorname{In}_{3 \mathrm{x}} \mathrm{N}_{\mathrm{x}} \mathrm{As}_{1-\mathrm{x}}$ films can be explained by considering the conduction band modifications by $\mathrm{N}$-induced anticrossing interaction. Since the maximum free electron concentration is determined by the Fermi energy with respect to $E_{\mathrm{FS}}$ (Ref.46) and because the position of the valence band in GaInNAs is independent of $\mathrm{N}$ concentration, the downward shift of the conduction band edge toward $E_{\mathrm{FS}}$ and the enhancement of the DOS effective mass in GaInNAs leads to a much larger concentration of uncompensated, electrically active donors for the same location of the Fermi energy relative to $E_{\mathrm{FS}}$. The calculated $n_{\max }$ as a function of $x$ for $\mathrm{Ga}_{1-3 \mathrm{x}} \mathrm{In}_{3 \mathrm{x}} \mathrm{N}_{\mathrm{x}} \mathrm{As}_{1-\mathrm{x}}$ only considering the downward shift of 
the conduction band caused by the band anticrossing, as well as that also including the increase in the effective mass can be obtained using ${ }^{48}$

$$
n\left(E_{F}\right)=\int \frac{\rho(E) d E}{1+\exp \left[\left(E-E_{F}\right) / k_{B} T\right]},
$$

where $\rho(E)$ is the perturbed density of states. The results are shown in Fig.6. Comparison of the experimental data with the calculation shows that in order to account for the large enhancement of the doping limits in III-N-V alloys both the effects of band gap reduction and the increase in the effective mass have to be taken into account.

While Se doped $\mathrm{Ga}_{1-3 \mathrm{x}} \mathrm{In}_{3 \mathrm{x}} \mathrm{N}_{\mathrm{x}} \mathrm{As} \mathrm{s}_{1-\mathrm{x}}$ alloys grown by MOCVD have shown enhanced $\mathrm{n}_{\max }$ in accordance with the BAC model, similar behavior is also observed in $\mathrm{S}^{+}$-implanted $\mathrm{GaN}_{x} \mathrm{As}_{1-\mathrm{x}}$ thin films. ${ }^{49}$ Figure 7 displays the carrier concentration profiles measured by the ECV technique for $\mathrm{S}$ implanted $\mathrm{GaN}_{\mathrm{x}} \mathrm{As}_{1-\mathrm{x}}(\mathrm{x} \sim 0.008)$ and SI-GaAs samples after RTA. A striking difference in the free electron concentration $n$ measured in the SI-GaAs and the $\mathrm{GaN}_{\mathrm{x}} \mathrm{As}_{1-\mathrm{x}}$ samples is observed. In the $\mathrm{S}^{+}$-implanted SI-GaAs sample, $n \sim 2.5 \times 10^{17} \mathrm{~cm}^{-3}$ was measured in the bulk of the implanted layer, with a higher $n \sim 5 \times 10^{17} \mathrm{~cm}^{-3}$ towards the end of the implantation profile. The theoretical $\mathrm{n}_{\max }$ in $\mathrm{GaN}_{\mathrm{x}} \mathrm{As}_{1-\mathrm{x}}$ due to the $\mathrm{N}$-induced conduction band modification within the framework of the BAC model and the amphoteric native defect model is $\sim 1 \times 10^{19} \mathrm{~cm}^{-3}$ for the $\mathrm{GaN}_{0.008} \mathrm{As}_{0.992}$ sample. This value is in a reasonably good agreement with the measured concentration of $6 \times 10^{18} \mathrm{~cm}^{-3}$ shown in Fig. 7 .

Attempts to form n-type $\mathrm{GaN}_{\mathrm{x}} \mathrm{As}_{1-\mathrm{x}}$ thin films with high electron concentration were also made by co-implantation of $\mathrm{N}$ and a dopant element in GaAs. ${ }^{50}$ Figure 8 shows a comparison of the ECV determined free electron concentration profiles for GaAs samples implanted with S alone and co-implanted with $\mathrm{S}$ and $\mathrm{N}(\mathrm{S}+\mathrm{N})$ after RTA at $945^{\circ} \mathrm{C}$ for $10 \mathrm{~s}$. The calculated as- 
implanted $\mathrm{S}$ and $\mathrm{N}$ atomic distributions are also shown in the figure. The most prominent difference in the electron concentration profiles between the $\mathrm{S}$ only and $(\mathrm{S}+\mathrm{N})$ samples is the much enhanced electron concentration in the $(\mathrm{S}+\mathrm{N})$ sample in a narrow region $(\sim 500 \AA)$ near the surface. The region with lower electron concentration at $\sim 0.1-0.2 \mu \mathrm{m}$ below the surface coincides with a region with excess As due to the implantation process that makes the substitution of $\mathrm{S}$ atoms into the As sites more difficult. ${ }^{50}$ In addition, larger concentrations of the compensating $\mathrm{V}_{\mathrm{Ga}}$ acceptors are also expected in the As-rich region. A reduced availability of group $\mathrm{V}$ sites and an increased $\mathrm{V}_{\mathrm{Ga}}$ concentration in the region lead to the minimum in the electron concentration. The effect is exacerbated in the $(\mathrm{S}+\mathrm{N})$ sample where both $\mathrm{S}$ and $\mathrm{N}$ compete for the same group $\mathrm{V}$ element sites.

Considering both band gap reduction and large increase in the electron effective mass, the high $\mathrm{n}_{\max }$ in the near-surface region of the $(\mathrm{S}+\mathrm{N})$ sample $\left(\sim 1.5 \times 10^{19} \mathrm{~cm}^{-3}\right)$ implies that the $\mathrm{N}$ content in this thin near-surface diluted nitride layer is $\mathrm{x}=0.0032$. This value is in good agreement with the calculated $\mathrm{N}$ concentration in the surface region $(\mathrm{x} \approx 0.003-0.01)$. With this $\mathrm{N}$ content the conduction band edge is shifted downward by $77 \mathrm{meV}$ and the conduction band effective mass at the Fermi energy becomes about three times larger than that of GaAs. ${ }^{51}$

\subsection{Decrease of electron mobility}

Incorporation of small amounts of nitrogen into GaAs to form $\mathrm{GaN}_{\mathrm{x}} \mathrm{As}_{1-\mathrm{x}}$ leads to a drastic reduction of the electron mobility. The mobility of $\mathrm{GaN}_{\mathrm{x}} \mathrm{As}_{1-\mathrm{x}}$ films ranges typically from about ten to a few hundred $\mathrm{cm}^{2} / \mathrm{Vs} .^{52,53}$ These values are over an order of magnitude smaller than the electron mobility in GaAs at comparable doping levels. Figure 9 shows the change in roomtemperature mobility of $\mathrm{Ga}_{0.93} \mathrm{In}_{0.07} \mathrm{~N}_{0.017} \mathrm{As}_{0.983}: \mathrm{Si}$ with the free electron concentration. The mobility shows a non-monotonic dependence on the electron concentration with a maximum at $n$ 
$\sim 5 \times 10^{18} \mathrm{~cm}^{-3}$. The room-temperature mobility $\left(\mu_{1}\right)$ is calculated from

$$
\mu=\frac{e \tau\left(k_{F}\right)}{m_{-}^{*}\left(\mathbf{k}_{F}\right)} \approx \frac{e \hbar}{m_{-}^{*}\left(\mathbf{k}_{F}\right) \cdot \Gamma_{-}\left(\mathbf{k}_{F}\right)},
$$

where $\Gamma_{-}\left(\mathbf{k}_{\mathrm{F}}\right)$ is the broadening of the dispersion relations. ${ }^{48}$ The short-dashed curve in Fig. 9 is the calculated result. Also shown is the Fermi energy as a function of $n$ calculated from Eq.(6). At high electron concentrations, when the Fermi energy approaches the original energy level of the $\mathrm{N}$ localized states in $\mathrm{In}_{0.07} \mathrm{Ga}_{0.93} \mathrm{As}_{0.983} \mathrm{~N}_{0.017}$ (located at $\sim 0.30 \mathrm{eV}$ above the conduction band edge of $E_{M}$, or $0.54 \mathrm{eV}$ above the $E_{-}$conduction-band edge), the mobility is largely suppressed by the strong hybridization between $\left|E_{N}\right\rangle$ and $\left|E_{M}(k)\right\rangle$. At $n=2 \times 10^{19} \mathrm{~cm}^{-3}$, the energy broadening and the scattering lifetime at the Fermi surface are estimated to be $0.25 \mathrm{eV}$ and $3 \times 10^{-15} \mathrm{~s}$, respectively. The mean free path of free electrons is about $5 \AA$, which is only a third of the average distance between the randomly distributed $\mathrm{N}$ atoms. Therefore, at this electron concentration the homogeneous broadening resulting from the anticrossing interaction is the dominant scattering mechanism that limits the electron mobility. As is seen in Fig. 9, at high concentrations the electron mobility calculated from the BAC model is in good quantitative agreement with experiment. It should be noted that this very good agreement has been obtained without any adjustable parameters.

At lower electron concentrations the mobility starts to decrease, deviating severely from $\mu_{1}$. This effect can be attributed to the scattering of the conduction electrons by the random fields caused by the structural and compositional disorder in the alloy. It is well known that in partially disordered semiconductors, as the Fermi level decreases from the degenerate doping into the non-degenerate doping regime, the conduction electrons experience increasingly strong scattering from the potential fluctuations. As a result the mobility decreases monotonically with 
decreasing electron concentration. ${ }^{54,55}$ In the case of $\mathrm{GaN}_{\mathrm{x}} \mathrm{As}_{1-\mathrm{x}}$ alloys the main contribution to the potential fluctuations originates from the random $\mathrm{N}$ distribution. An estimate for the electron mobility limited by the random field scattering $\left(\mu_{2}\right)$ is shown in Fig. 9. The solid curve in the figure includes the contributions from both effects, level broadening and random alloy scattering that limit the overall mobility $\mu=1 /\left(\mu_{1}^{-1}+\mu_{2}^{-1}\right)$. This calculated mobility reproduces the nonmonotonic behavior of the mobility measured over two decades of change in electron concentration.

\subsection{Mutual passivation in dilute nitrides}

In contrast to the observed enhancement of the doping activation of the group-VI elements ( $\mathrm{S}, \mathrm{Se}$ ), co-implantation of $\mathrm{Si}$ and $\mathrm{N}$ into GaAs was found to only produce highly resistive materials. ${ }^{56}$ This asymmetry in the behavior of groups VI and IV donors reveals an entirely new effect in which an electrically active substitutional group-IV donor and an isovalent $\mathrm{N}$ atom passivate each other's electronic effects. ${ }^{57}$ This passivation occurs via the formation of nearest neighbor $\mathrm{IV}_{\mathrm{Ga}}-\mathrm{N}_{\mathrm{As}}$ pairs in $\mathrm{GaN}_{\mathrm{x}} \mathrm{As}_{1-\mathrm{x}}$ doped with group-IV donors ( $\mathrm{Si}$ and $\mathrm{Ge}$ ).

Figure 10 shows the measured free electron concentration in MBE-grown Si-doped GaAs and $\mathrm{Ga}_{0.93} \mathrm{In}_{0.07} \mathrm{~N}_{0.017} \mathrm{As}_{0.983}$ epitaxial films, as well as an MOCVD-grown Se-doped $\mathrm{Ga}_{0.92} \mathrm{In}_{0.08} \mathrm{~N}_{0.024} \mathrm{As}_{0.976}$ thin film after RTA for $10 \mathrm{sec}$ in the temperature range of $650-950^{\circ} \mathrm{C}$. The Si and Se doping levels in these samples are in the range of $2-9 \times 10^{19} \mathrm{~cm}^{-3}$ and $\sim 2 \times 10^{20} \mathrm{~cm}^{-3}$, respectively. For the GaAs:Si and GaInNAs:Se samples, only slight decreases in electron concentrations, from $1.6 \times 10^{19}$ to $8 \times 10^{18} \mathrm{~cm}^{-3}$ for GaAs:Si and from $3 \times 10^{19}$ to $2 \times 10^{19} \mathrm{~cm}^{-3}$ for GaInNAs:Se, were observed as the result of high temperature RTA. Such a decrease in the electron concentration in GaAs is in agreement with the equilibrium maximum electron concentration (in the range of $10^{18} \sim 10^{19} \mathrm{~cm}^{-3}$ ). ${ }^{58}$ The much higher electron concentration in the Se 
doped GaInNAs sample is also consistent with the enhanced donor activation efficiency resulting from the $\mathrm{N}$-induced modification of the conduction band structure discussed above. On the other hand, however, the free electron concentration in the GaInNAs:Si sample drops from $1.1 \times 10^{19} \mathrm{~cm}^{-3}$ in the as-grown film to $3 \times 10^{17} \mathrm{~cm}^{-3}$ after RTA at $950^{\circ} \mathrm{C}$ for $10 \mathrm{~s}$. In fact, RTA at $950^{\circ} \mathrm{C}$ for $120 \mathrm{~s}$ reduces the electron concentration further down to $<10^{15} \mathrm{~cm}^{-3}$. The reduced electrical activity of $\mathrm{Si}$ donors in $\mathrm{GaN}_{\mathrm{x}} \mathrm{As}_{1-\mathrm{x}}$ alloys can be attributed to the formation of nearest neighbor $\mathrm{Si}_{\mathrm{Ga}}-\mathrm{N}_{\mathrm{As}}$ pairs. The highly electronegative $\mathrm{N}$ atom strongly binds the fourth valence electron of $\mathrm{Si}$ and effectively deactivates the non-bonding electron. Consequently, the donor activity of the $\mathrm{Si}$ is passivated. This picture suggests that, because of the localized nature of the $\mathrm{N}$-states in $\mathrm{GaN}_{\mathrm{x}} \mathrm{As}_{1-\mathrm{x}}$, the passivation is limited to group-IV donors that occupy Ga sites. This is supported by the small change in electrical behavior observed in the GaInNAs:Se thin film in which both the $\mathrm{N}$ and Se reside in the As sublattice and therefore cannot form nearest neighbor passivating pairs. It should be pointed out that the mutual passivation effect discussed here differs from the previously observed, much less stable and reversible passivation of the activity of $\mathrm{N}$ atoms with hydrogen. ${ }^{59}$ In the latter case hydrogen does not have any effect on the material properties by itself.

The well-defined onset temperature of about $700^{\circ} \mathrm{C}$ for the observed reduction of electron concentration in GaInNAs:Si shown in Fig. 10 roughly corresponds to the annealing condition that allows the $\mathrm{Si}$ atoms to diffuse over a length equal to the average distance between randomly distributed Si and $\mathrm{N}$ atoms $(\sim 7 \AA) \cdot{ }^{57}$ The diffusion-controlled passivation process is analyzed in the context of Si diffusion mediated by both neutral $\mathrm{Ga}$ vacancies $\left(\mathrm{V}_{\mathrm{Ga}}{ }^{0}\right)$ and triply negatively charged $\mathrm{Ga}$ vacancies $\left(\mathrm{V}_{\mathrm{Ga}}{ }^{3-}\right){ }^{60}$ Figure 11 shows the isothermal annealing effects of the normalized free carrier concentration of the GaInNAs:Si sample for annealing temperatures in 
the range of $650-820^{\circ} \mathrm{C}$. Calculations based on $\mathrm{Si}$ diffusion via $\mathrm{V}_{\mathrm{Ga}}{ }^{0}$ and $\mathrm{V}_{\mathrm{Ga}}{ }^{3-}$ vacancies are shown as dashed lines in the figure. The calculations agree very well with the experimental data. According to the diffusion model, at high annealing temperatures or long annealing time, the Fermi-level independent, $\mathrm{V}_{\mathrm{Ga}}{ }^{0}$-mediated diffusion becomes increasingly important. This is reflected in the fact that the $\ln \left[n / n_{0}\right] \sim t$ curves approach a linear dependence at high temperatures or long anneal times.

Since isoelectronic $\mathrm{N}$ is responsible for a massive modification of the electronic structure of $\mathrm{GaN}_{\mathrm{x}} \mathrm{As}_{1-\mathrm{x}}$ alloys, the question arises to what extent the passivation process affects the $\mathrm{N}$ induced modification of the electronic structure of the alloys. PR measurements on the GaInNAs:Si sample show that the band gap energy increases with increasing RTA temperature. Annealing of the sample at $950^{\circ} \mathrm{C}$ increases the gap by about $35 \mathrm{meV}$. If this increase is attributed to deactivation of the $\mathrm{N}$ atoms, the concentration of the deactivated $\mathrm{N}$ is approximately equal to $0.004 \times 2.2 \times 10^{22} \mathrm{~cm}^{-3} \approx 8 \times 10^{19} \mathrm{~cm}^{-3}$, which is close to the initial total Si concentration in the as-grown sample. This is consistent with the formation of $\mathrm{Si}_{\mathrm{Ga}}-\mathrm{N}_{\mathrm{As}}$ pairs being responsible for the mutual passivation of both species. This scenario of the passivation process is further corroborated by PL measurements on the GaInNAs:Si sample. A strong PL emission peaked at $\sim 0.8 \mathrm{eV}$ is observed when the sample is mutually passivated, indicating the presence of deep states most likely associated with the $\mathrm{Si}_{\mathrm{Ga}}-\mathrm{N}_{\mathrm{As}}$ pairs.

The general nature of the mutual passivation effect is supported by the investigations of $\mathrm{GaN}_{\mathrm{x}} \mathrm{As}_{1-\mathrm{x}}$ layers doped with Ge, another group IV donor. Ge doped $\mathrm{GaN}_{\mathrm{x}} \mathrm{As}_{1-\mathrm{x}}$ layers were synthesized by sequential implantation of Ge and $\mathrm{N}$ ions into GaAs followed by a combination of PLM and RTA. The passivation of the $\mathrm{N}$ activity by the Ge atoms is illustrated in the series of PR spectra presented in Fig. 12. The band gap energies obtained from the PR spectra are shown 
in the inset as a function of the duration of $950^{\circ} \mathrm{C}$ RTA. A fundamental band gap transition at $1.24 \mathrm{eV}$ is observed for GaAs samples implanted with $2 \% \mathrm{~N}$ alone after PLM-RTA at $950^{\circ} \mathrm{C}$ for 10-120s, corresponding to a $\mathrm{GaN}_{\mathrm{x}} \mathrm{As}_{1-\mathrm{x}}$ layer with $\mathrm{x} \sim 0.01$. In contrast, the band gap of the samples co-implanted with $\mathrm{N}$ and $\mathrm{Ge}(2 \% \mathrm{~N}+2 \% \mathrm{Ge})$ after PLM increases from 1.24 to $1.42 \mathrm{eV}$ (band gap of GaAs) as the RTA duration increases to $60 \mathrm{~s}$, revealing that nearly all $\mathrm{N}_{\mathrm{As}}$ sites are passivated by Ge. The gradual increase in the band gap of the $2 \% \mathrm{~N}+2 \% \mathrm{Ge}$ sample as a function of RTA temperature and/or time duration can be attributed to the passivation of $\mathrm{N}_{\mathrm{As}}$ by $\mathrm{Ge}_{\mathrm{Ga}}$ through the formation of nearest neighbor $\mathrm{Ge}_{\mathrm{Ga}}-\mathrm{N}_{\mathrm{As}}$ pairs.

Figure 13 shows a comparison of the electron concentration of the $2 \% \mathrm{~N}+2 \% \mathrm{Ge}$ and $2 \% \mathrm{Ge}$ samples followed by PLM-RTA for $10 \mathrm{~s}$ in the temperature range of 650 to $950^{\circ} \mathrm{C}$. The electron concentration of both samples approaches $10^{19} \mathrm{~cm}^{-3}$ after PLM. For the $2 \%$ Ge sample, thermal annealing after PLM drives the system toward equilibrium with an electron concentration of $\sim 1 \times 10^{18} \mathrm{~cm}^{-3}$ which is consistent with the amphoteric character of Ge in GaAs. ${ }^{61}$ The electron concentration of the $2 \% \mathrm{~N}+2 \% \mathrm{Ge}$ samples, on the other hand, drops over two orders of magnitude to less than $10^{17} \mathrm{~cm}^{-3}$ as the samples are subjected to RTA at temperatures higher than $650^{\circ} \mathrm{C}$. The changes in the band gap and the electrical behavior in the Ge doped $\mathrm{GaN}_{\mathrm{x}} \mathrm{As}_{1-\mathrm{x}}$ sample show that the Ge donors and isovalent $\mathrm{N}$ passivate each other via the formation of $\mathrm{N}_{\mathrm{As}^{-}}$ $\mathrm{Ge}_{\mathrm{Ga}}$ pairs, just as was the case in Si doped $\mathrm{GaN}_{\mathrm{x}} \mathrm{As}_{1-\mathrm{x}}$. Mutual passivation of $\mathrm{Si}$ and $\mathrm{N}$ has been also observed in Si doped $\mathrm{Ga}_{0.48} \mathrm{In}_{0.52} \mathrm{~N}_{\mathrm{x}} \mathrm{P}_{1-\mathrm{x} .}{ }^{62}$ All these results clearly demonstrate the general nature of this phenomenon.

\section{Conclusions}

The effect of $\mathrm{N}$ on the electronic band structure in dilute III-N-V nitrides has been explained in terms of a band anti-crossing interaction between highly localized $\mathrm{N}$ states and the 
extended conduction-band states of the semiconductor matrix. The interaction leads to a splitting of the conduction band into two nonparabolic subbands. The downward shift of the lower subband edge relative to the valence band is responsible for the reduction of the fundamental bandgap. The profound effects on the optical and electrical properties of the dilute nitrides such as the significant increase in the electron effective mass and the drastic decrease in the electron mobility can all be quantitatively account for using this model.

\section{Acknowledgements}

The authors are very grateful to Dr. J.F. Geisz and Prof. C.W. Tu for providing the samples used in this study. This work is supported by the Director, Office of Science, Office of Basic Energy Sciences, Division of Materials Sciences and Engineering, of the U.S. Department of Energy under Contract No. DE-AC03-76SF00098. 


\section{References}

1. M. Weyers, M. Sato, H. Ando, Jpn. J. Appl. Phys. 31, L853 (1992).

2. M. Kondow, K. Uomi, K. Hosomi and T. Mozume, Jpn. J. Appl. Phys. 33, L1056 (1994).

3. C. Skierbiszewski, P. Perlin, P. Wisniewski, W. Knap, T. Suski, W. Walukiewicz, W. Shan, K.M. Yu, J.W. Ager, E.E. Haller, J.F. Geisz, and J.M. Olson, Appl. Phys. Lett. 76, 2409(2000).

4. J.F. Geisz, D.J. Friedman, J.M. Olson, S.R. Kurtz, and M.B. Keyes, J. Cryst. Growth, 195, 401(1998).

5. S.R. Kurtz, Allerman, C.H. Seager, R.M. Sieg, and E.D. Jones, Appl. Phys. Lett. 77, 400(2000).

6. W. Shan, W. Walukiewicz, J. W. Ager III, E. E. Haller, J. F. Geisz, D. J. Friedman, J. M. Olson, and S. R. Kurtz, Phys. Rev. Lett. 82, 1221(1999).

7. J. D. Perkins, A. Masceranhas, Y. Zhang, J. F. Geisz, D. J. Friedman, J. M. Olson, and S. R. Kurtz, Phys. Rev. Lett. 82, 3312(1999).

8. K. Uesugi, N. Marooka and I. Suemune, Appl. Phys. Lett. 74, 1254(1999).

9. M. Weyers, M. Sato and H. Ando, Jpn. J. Appl. Phys., 31, L853(1992).

10. J. N. Baillargeon, K. Y. Cheng, G. E. Hofler, P. J. Pearah and K. C. Hsieh, Appl. Phys. Lett. 60, 2540(1992).

11. X. Liu, S.G. Bishop, J.N. Baillargeon, and K.Y. Cheng, Appl. Phys. Lett. 63, 208(1993).

12. W. G. Bi and C. W. Tu, J. Appl. Phys., 80, 1934 (1996); Appl. Phys. Lett. 69, 3710(1996); Appl. Phys. Lett., 72, 1161(1998).

13. M. Kondow, T. Kitatani, S. Nakatsuka, M. C. Larson, K. Nakahara, Y. Yazawa, M. Okai and K Uomi, IEEE J. Sel. Topics in Quantem Elect., 3, 719 (1997). 
14. M. Kondow, T. Kitatani, M. C. Larson, K. Nakahara, K. Uomi and H. Inoue, J. Crystal Growth, 188, 255 (1998).

15. H. P. Xin and C. W. Tu, Appl. Phys. Lett., 72, 2442 (1998).

16. G. Pozina, I. Ivanov, B. Monemar, J.V. Thordson, and T.G. Andersson, J. Appl. Phys. 84, $3830(1998)$.

17. D. J. Friedman, J. F. Geisz, S. R. Kurtz, D. Myers and J. M Olson, J. Cryst. Growth, 195, 409(1998).

18. S.R. Kurtz, A.A. Allerman, E.D. Jones, J.M. Gee, J.J. Banas, and B.E. Hammons, Appl. Phys. Lett. 74, 729(1999).

19. E.V.K. Rao, A. Ougazzaden, Y. LeBellego, and M. Juhel, Appl. Phys. Lett. 72, 1409(1998).

20. S. Sakai, Y. Ueta and Y. Terauchi, Jpn. J. Appl. Phys., 32, 4413(1993).

21. A. Rubio and M.L. Cohen, Phys. Rev. B51, 4343(1995).

22. J. Neugebauer and C.G. Van de Walle, Phys . Rev. B51, 10568(1995).

23. S.-H. Wei and A. Zunger, Phys. Rev. Lett., 76, 664 (1996).

24. L. Bellaiche, S.-H. Wei and A Zunger, Phys. Rev. B54, 17568 (1996); B56, 10233(1997).

25. E.D. Jones, N.A. Modine, A.A. Allerman, S.R. Kurtz, A.F. Wright, S.T. Tozer, and X. Wei, SPIE proc. Vol.3621, 52(1999); Phys. Rev. B60, 4430(1999).

26. T. Mattila, S.H. Wei, and A. Zunger, Phys. Rev. B60, R11245(1999).

27. W. Walukiewicz, W. Shan, J. W. Ager III, D. R. Chamberlin, E. E. Haller, J. F. Geisz, D. J. Friedman, J. M. Olson, and S. R. Kurtz, in Photovoltaics for the $21^{\text {st }}$ Century, ed. V.K. Kapur, R.D. McDonnell, D. Carlson, G.P. Ceasar, and A. Rohatgi, (The Electrochemical Society, Pennington, NJ, 1999), p.199.

28. H.P. Hjalmarson, P. Vogl, D.J. Wolford, J.D. Dow, Phys. Rev. Lett. 44, 810(1980). 
29. D.J. Wolford, J.A. Bradley, K. Fry, J. Thompson, in Physics of Semicondutors, ed. J.D. Chadi and W.A. Harrison (Springer, New York, 1984), p.627.

30. X. Liu, M.-E. Pistol, L Samuelson, S. Schwetlick and W. Seifert, Appl. Phys. Lett., 56, 1451(1990).

31. Y. Makita, H. Ijuin, and S. Gonda, Appl. Phys. Lett. 28, 287(1976).

32. A. Lindsay and E.P. O'Reilly, Solid State Commun. 112, 443(1999).

33. E.P. O'Reilly, A. Lindsay, S. Tomic, and M. Kamal-Saadi, Semicond. Sci. Technol. 17, $870(2002)$.

34. P.J. Klar, H. Gruning, J. Koch, S. Schafer, K. Volz, W. Stolz, W. Heimbrodt, A.M. KamalSaadi, A. Lindsay, and E.P. O’Reilly, Phys. Rev. B64, 121203(2001).

35. P.J. Klar, H. Gruning, W. Heimbrodt, G. Weiser, J. Koch, S. Schafer, K. Volz, W. Stolz, S.W. Koch, S. Tomic, S.A. Chouli, T.J.C. Hosea, E.P. O’Reilly, M. Hofmann, J. Hader, and J.V. Moloney, Semicond. Sci. Technol, 17, 830(2002).

36. W. Shan, K.M. Yu, W. Walukiewicz, J.W. Ager III, E.E. Haller, M.C. Ridgway, Appl. Phys. Lett. 75, 1410(1999).

37. K.M. Yu, W. Walukiewicz, J. Wu, J. Beeman, J.W. Ager III, E.E. Haller, W. Shan, H.P. Xin, C.W. Tu, M.C. Ridgway. Appl. Phys. Lett. 78, 1077(2001); J. Appl. Phys. 90, 2227(2001).

38. J. Jasinski, K.M. Yu, W. Walukiewicz, Z. Liliental-Weber, J. Washburn, Appl. Phys. Lett. 79, 931(2001).

39. K.M. Yu, W. Walukiewicz, M.A. Scarpulla, O.D. Dubon, J. Jasinski, Z. Liliental-Weber, J. Wu, J. Beeman, M.R. Pillai, M.J. Aziz, J. Appl. Phys. 94, 1043(2003).

40. K.M. Yu, W. Walukiewicz, J. Wu, W. Shan, J. Beeman, M.A. Scarpulla, O.D. Dubon, M.C. Ridgway, D.E. Mars, D.R. Chamberlin, Appl. Phys. Lett., 83, 2844(2003). 
41. C.W. White, P.S. Percy, Laser and Electron Beam Processing of Materials, Academic Press, (New York 1980).

42. J.S. Williams, In: Laser Annealing of Semiconductors. Ed. J.M. Poate and J.M. Mayer, Academic Press, (New York, 1982), p.385.

43. W. Shan, W. Walukiewicz, J.W. Ager III, E.E. Haller, J.F. Geisz, D.J. Friedman, J.M. Olson, and S.R. Kurtz, J. Appl. Phys. 86, 2349(1999).

44. W. Walukiewicz, Appl. Phys. Lett. 54, 2094(1989); Mat. Res. Soc. Symp. Proc. 300, 421(1993).

45. S.B. Zhang, S.H. Wei, A. Zunger. J. Appl. Phys. 83, 3192(1998;).

46. W. Walukiewicz, Mats. Science Forum, Vols.143-147, 519(1993).

47. K.M. Yu, W. Walukiewicz, W. Shan, J.W. Ager III, J. Wu, E.E. Haller, J.F. Geisz, D.J. Friedman, J.M. Olson. Phys. Rev. B61, R13337(2000).

48. J. Wu, W. Shan, W. Walukiewicz, Semicond. Sci. Technol. 17, 860(2002).

49. K.M. Yu, W. Walukiewicz, W. Shan, J. Wu, J.W. Ager III, E.E. Haller, J.F. Geisz, M.C. Ridgway, Appl. Phys. Lett. 77, 2858(2000).

50. K.M. Yu, W. Walukiewicz, W. Shan, J. Wu, J. Beeman, J.W. Ager III, E.E. Haller. App. Phys. Lett. 77, 3607(2000).

51. C. Skierbiszewski, P. Perlin, P. Wišniewski, W. Knap, T. Suski, W. Walukiewicz, W. Shan, K.M. Yu, J.W. Ager III, E.E. Haller, J.F. Geisz, J.M. Olson. Appl. Phys. Lett. 76, 2409(2000).

52. J.F. Geisz, D.J. Friedman, J.M. Olson, S.R. Kurtz, B.M. Keyes, J. Crystl. Growth, 195, 401(1998). 
53. S.R. Kurtz, A.A. Allerman, C.H. Seager, R.M. Sieg, E.D. Jones, Appl. Phys. Lett. 77, 400(2000).

54. V.L. Bonch-Bruevich, Phys. Stat. Sol. 42, 35(1970).

55. P.G. Zhumatii, Phys. Stat. Sol. (b)75, 61(1976).

56. K.M. Yu, Semicond. Sci. Tedchnol. 17, 785(2002).

57. K.M. Yu, W. Walukiewicz, J. Wu, D.E. Mars, D.R. Chamberlin, M.A. Scarpulla, D.O. Dubon, J.F. Geisz, Nature Materials, 1, 185(2002).

58. W. Walukiewicz, Physica, B302-303, 123(2001).

59. A. Polimeni, G. Baldassarri H. v., H.M. Bissiri, M. Capizzi, M. Fischer, M. Reinhardt, and A. Forchel, Phys. Rev. B63, 201304(2001).

60. J. Wu, K.M. Yu, W. Walukiewicz, G. He, E.E. Haller, D.E. Mars, D.R. Chamberlin, Phys. Rev. B68, 195202(2003).

61. Y.K. Yeo, J.E. Ehret, F.L. Pedrotti, Y.S. Park, W.M. Theis, Appl. Phys. Lett. 35, 197(1979).

62. Y.G. Hong, A.Nishikawa, and C.W. Tu, Appl. Phys. Lett. 83, 5446(2003). 


\section{Figure Captions}

Figure 1. Illustration of the effects of band anticrossing on the conduction band structure in the vicinity of $\Gamma$-point minimum. (a) The highly electronegative isoelectronic $\mathrm{N}$ induced localized state resonant with the conduction band; (b) The localized state located below the conduction band. The solid lines are the restructured $E_{-}$and $E_{+}$subbands resulting from the band anticrossing interaction between the localized states (dash-dotted line) and the extended states of the conduction band (broken line).

Figure 2. PR spectra measured from a series of samples implanted with increasing amounts of $\mathrm{N}$ $\left(\mathrm{x}_{\text {imp }}\right)$ and processed by PLM at an energy fluence of $0.34 \mathrm{~J} / \mathrm{cm}^{2}$ and subsequent RTA at $950^{\circ} \mathrm{C}$ for $10 \mathrm{sec}$.

Figure 3. PR spectra of $\mathrm{GaN}_{\mathrm{x}} \mathrm{As}_{1-\mathrm{x}}$ samples with different $\mathrm{N}$ concentrations.

Figure 4. Effects of pressure on the optical transitions associated with the $E_{-}$and $E_{+}$transitions in $\mathrm{GaN}_{0.015} \mathrm{As}_{0.985}$ and $\mathrm{Ga}_{0.95} \operatorname{In}_{0.05} \mathrm{~N}_{0.012} \mathrm{As}_{0.988}$.

Figure 5. The $\mathrm{E}_{-}$and $\mathrm{E}_{+}$transition energies measured for $\mathrm{Al}_{\mathrm{y}} \mathrm{Ga}_{1-\mathrm{y}} \mathrm{N}_{\mathrm{x}} \mathrm{As}_{1-\mathrm{x}}$ samples. Open circles represent $\mathrm{E}_{0}$ transitions in samples without $\mathrm{N}(\mathrm{x}=0)$. The dependence of the $\Gamma, \mathrm{X}$ and $\mathrm{L}$ conduction band edges on the AlAs mole fraction in $\mathrm{Al}_{\mathrm{y}} \mathrm{Ga}_{1-\mathrm{y}} \mathrm{As}$ alloys are shown by the solid lines. The dashed line represents the estimated change of the $E_{N}$ position with Al content. The inset shows a comparison of PR spectra measured on the $\mathrm{Al}_{0.35} \mathrm{Ga}_{0.65} \mathrm{As}$ samples with (solid line) and without $\mathrm{N}$ (dashed line).

Figure 6. Comparison of the measured maximum electron concentration with the calculated values as a function of $\mathrm{N}$ fraction in $\mathrm{Ga}_{1-3 \mathrm{x}} \mathrm{In}_{3 \mathrm{x}} \mathrm{N}_{\mathrm{x}} \mathrm{As}_{1-\mathrm{x}}$. Two different cases of the calculated $\mathrm{n}_{\max }$ are shown: one includes effects of downward shift of the conduction band only (dashed curve) and the other includes both the band shift and the enhancement of the density of states (solid 
curve). The calculated $\mathrm{n}_{\max }$ for samples without $\mathrm{N}$ (i.e. when only the effects from the bandgap lowering produced by In incorporation are considered) are also shown (dotted curve) for comparison. The shaded area indicates the range of Se concentration in these samples.

Figure 7. Ionized net donor concentration profiles for the $\mathrm{GaN}_{\mathrm{x}} \mathrm{As}_{1-\mathrm{x}}$ films and the SI-GaAs standard measured by the electrochemical capacitance-voltage (ECV) technique. The short-dashed curve is the calculated distribution of implanted S atoms. The dashed horizontal lines indicate the theoretical free electron concentrations in $\mathrm{Ga}_{1-\mathrm{x}} \mathrm{N}_{\mathrm{x}} \mathrm{As}$ by considering only the effects of the downward shift of the conduction band (band edge only) and both the effects of band gap reduction and density of states effective mass enhancement (band edge + effective mass).

Figure 8. The ECV measured net donor concentration profiles for the GaAs samples implanted with $\mathrm{S}$ alone and $\mathrm{S}+\mathrm{N}$ after RTA at $945^{\circ} \mathrm{C}$ for 10 s. The calculated atomic profiles for both the implanted $\mathrm{S}$ and $\mathrm{N}$ are also shown.

Figure 9. Room-temperature electron mobility of $\mathrm{Ga}_{0.93} \mathrm{In}_{0.07} \mathrm{~N}_{0.017} \mathrm{As}_{0.983}$ : Si plotted as a function of electron concentration. The calculated mobilities limited by the conduction band broadening $\left(\mu_{1}\right)$ and by the random field scattering $\left(\mu_{2}\right)$ are shown. The calculated Fermi energy is referenced to the bottom of the lowest conduction band $\left(E_{-}\right)$.

Figure 10. Electron concentrations of $\mathrm{Si}$ doped GaAs and $\mathrm{Ga}_{0.93} \mathrm{In}_{0.07} \mathrm{~N}_{0.017} \mathrm{As}_{0.983}$ as a function of annealing temperature for $10 \mathrm{~s}$. The dependence of the electron concentration on RTA temperature for a MOCVD-grown Se-doped $\mathrm{Ga}_{0.92} \mathrm{In}_{0.08} \mathrm{~N}_{0.024} \mathrm{As}_{0.976}$ film is also included.

Figure 11. Normalized free electron concentration as a function of annealing time at different annealing temperatures. The dashed curves represent the results from analytical calculations based on Si diffusion via Ga vacancies. 
Figure 12. PR spectra measured from a series of ion beam synthesized Ge doped $\mathrm{GaN}_{\mathrm{x}} \mathrm{As}_{1-\mathrm{x}}$ samples RTA at $950^{\circ} \mathrm{C}$ for durations of $5 \sim 120 \mathrm{~s}$. The inset shows the band gap energies determined from the PR measurements.

Figure 13. Free electron concentrations of the $2 \% \mathrm{Ge}$ and $2 \% \mathrm{~N}+2 \% \mathrm{Ge}$ samples after PLM+RTA at increasing temperature for $10 \mathrm{~s}$ obtained by Hall effect measurements. Electron concentration for the $2 \% \mathrm{~N}+2 \% \mathrm{Ge}$ sample after PLM+RTA at $950^{\circ} \mathrm{C}$ for $60 \mathrm{~s}$ is also shown. 

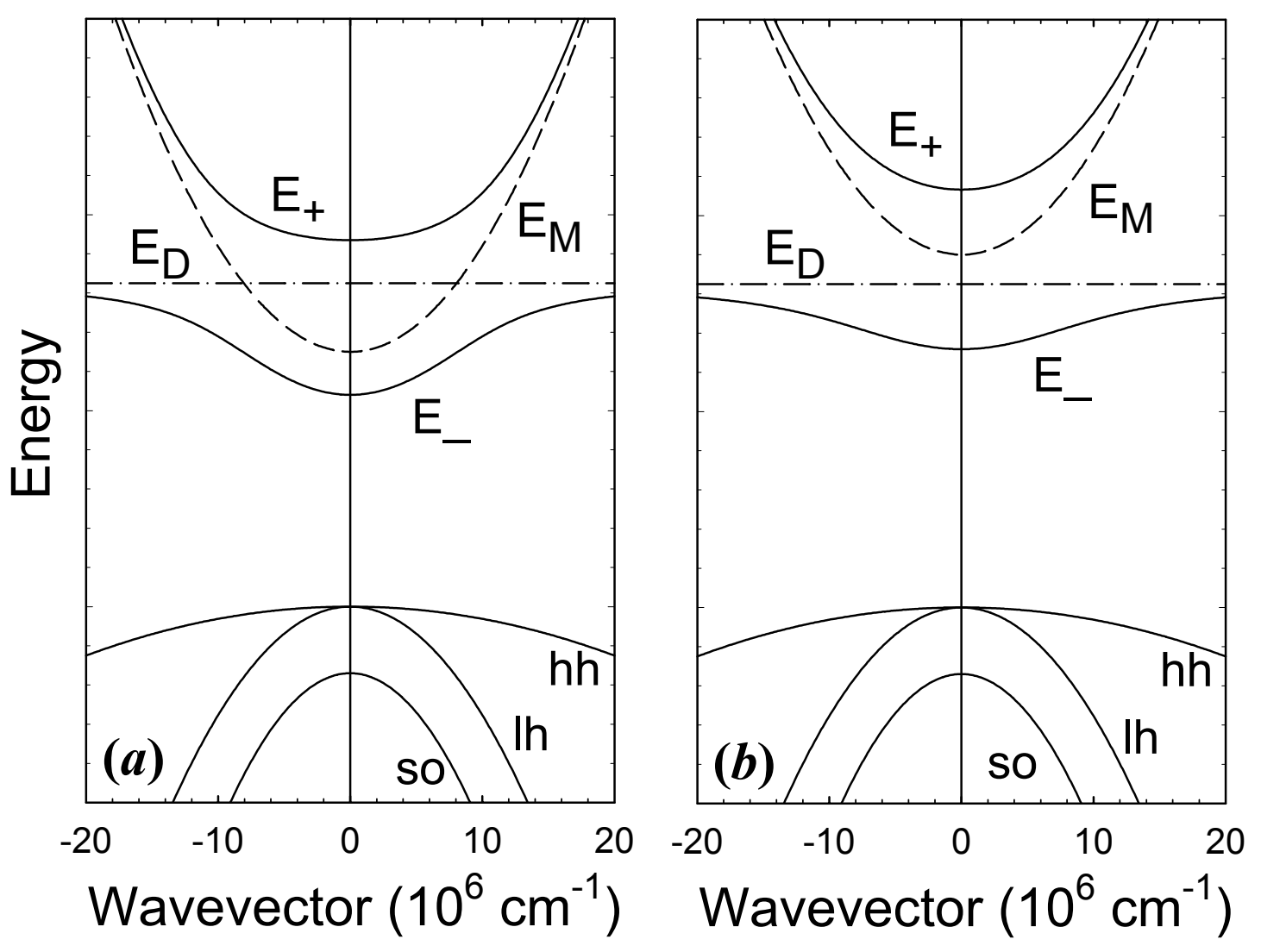

Figure 1 


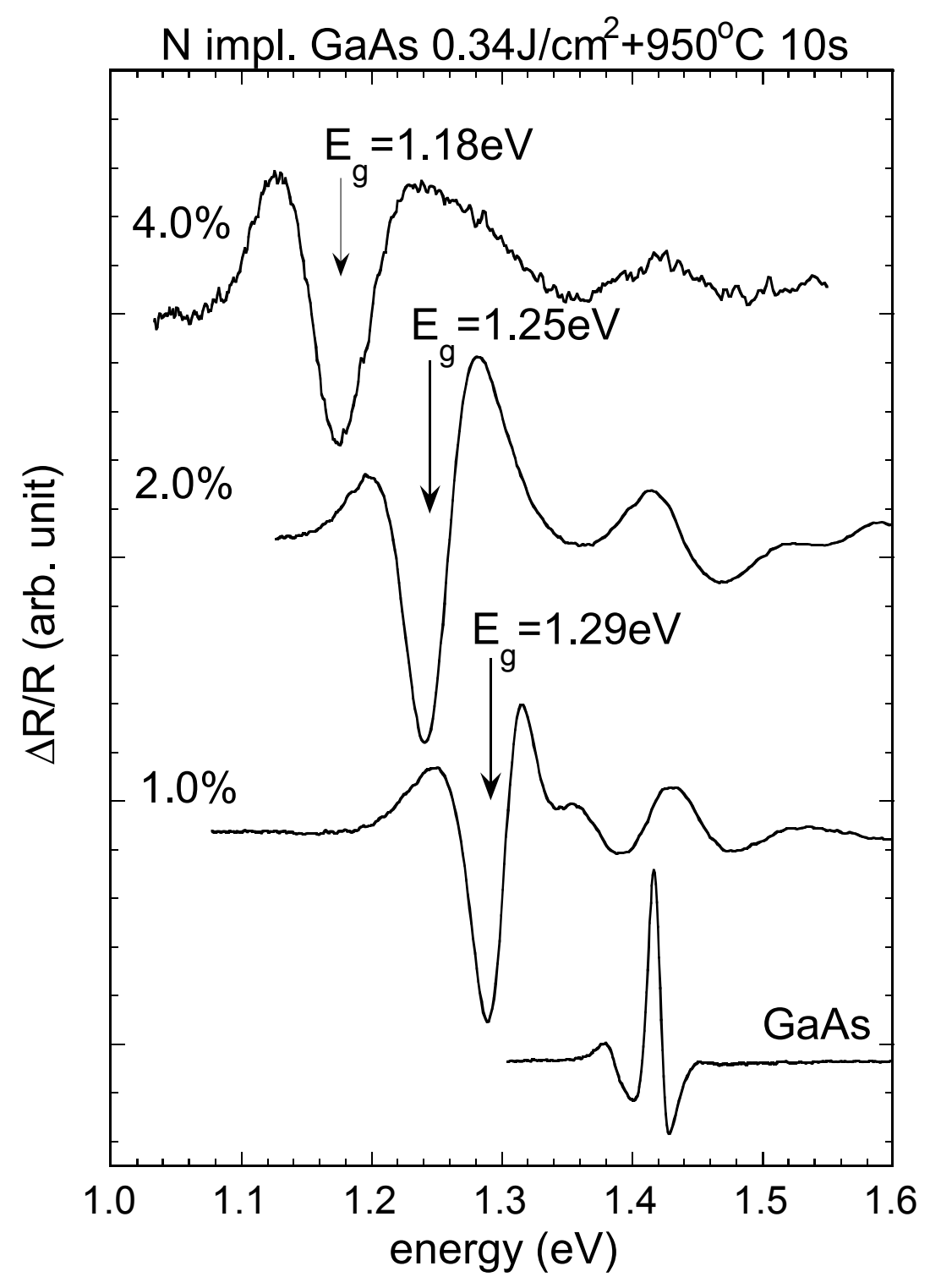

Figure 2 


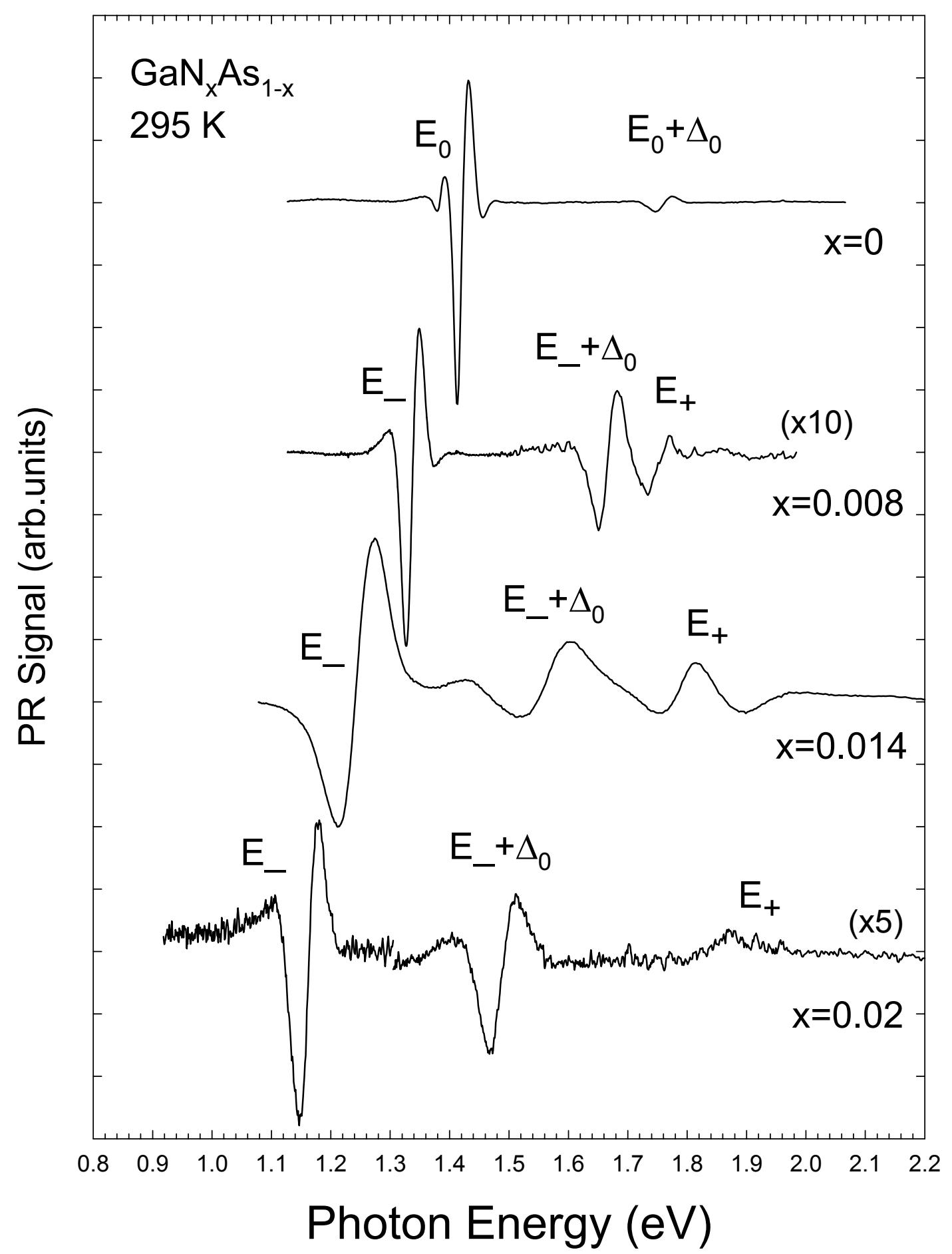

Figure 3 


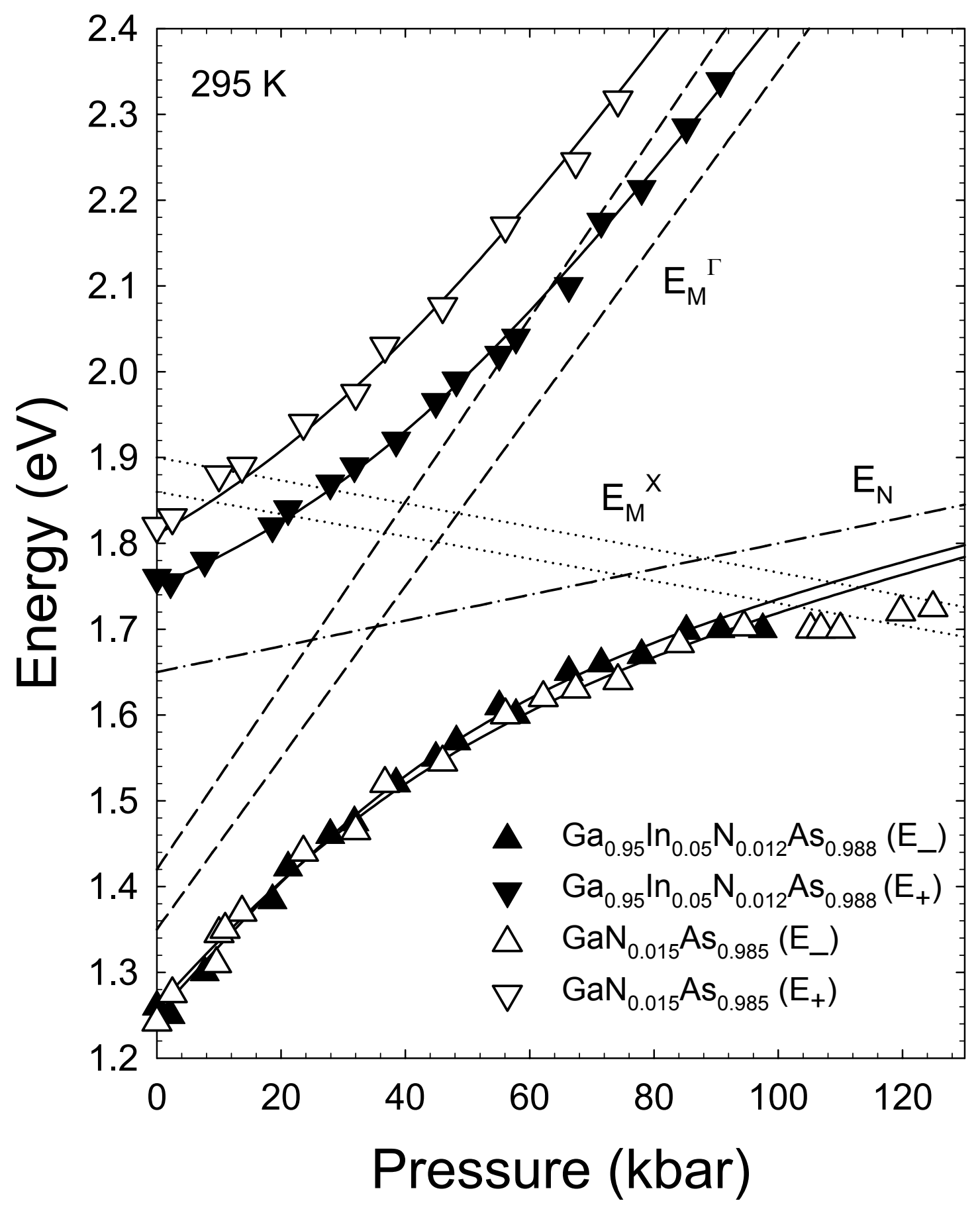

Figure 4 


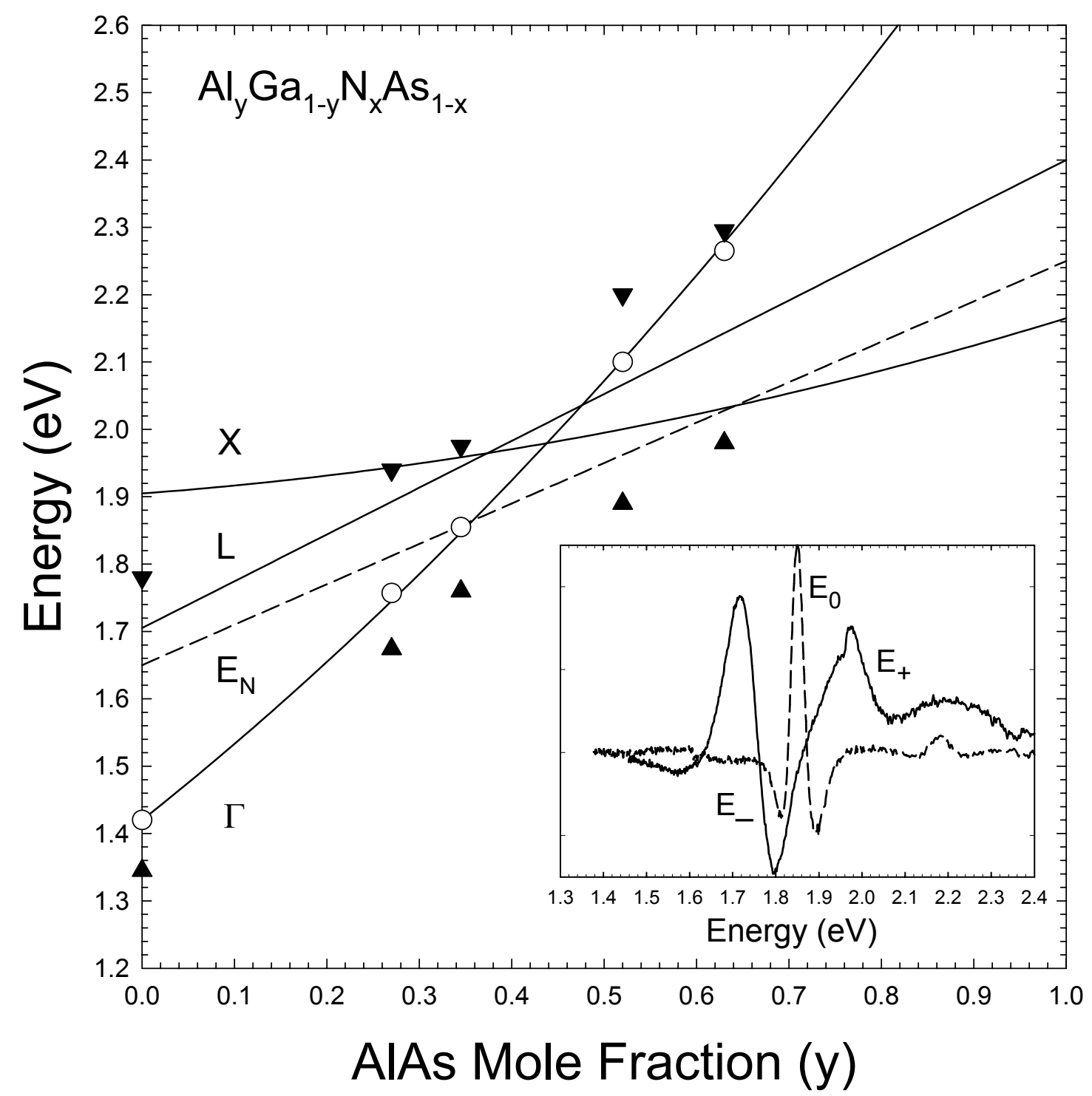

Figure 5 


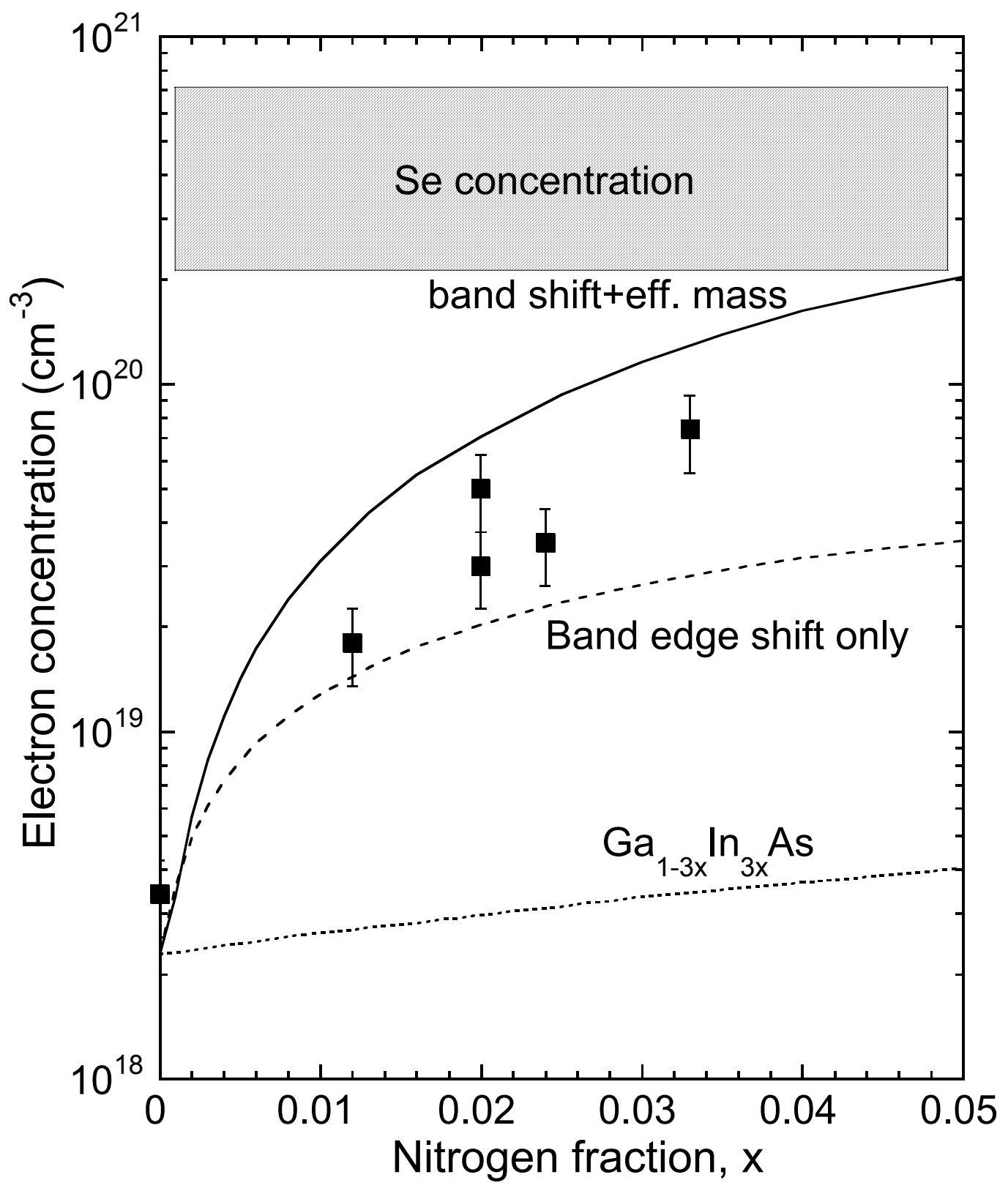

Figure 6 


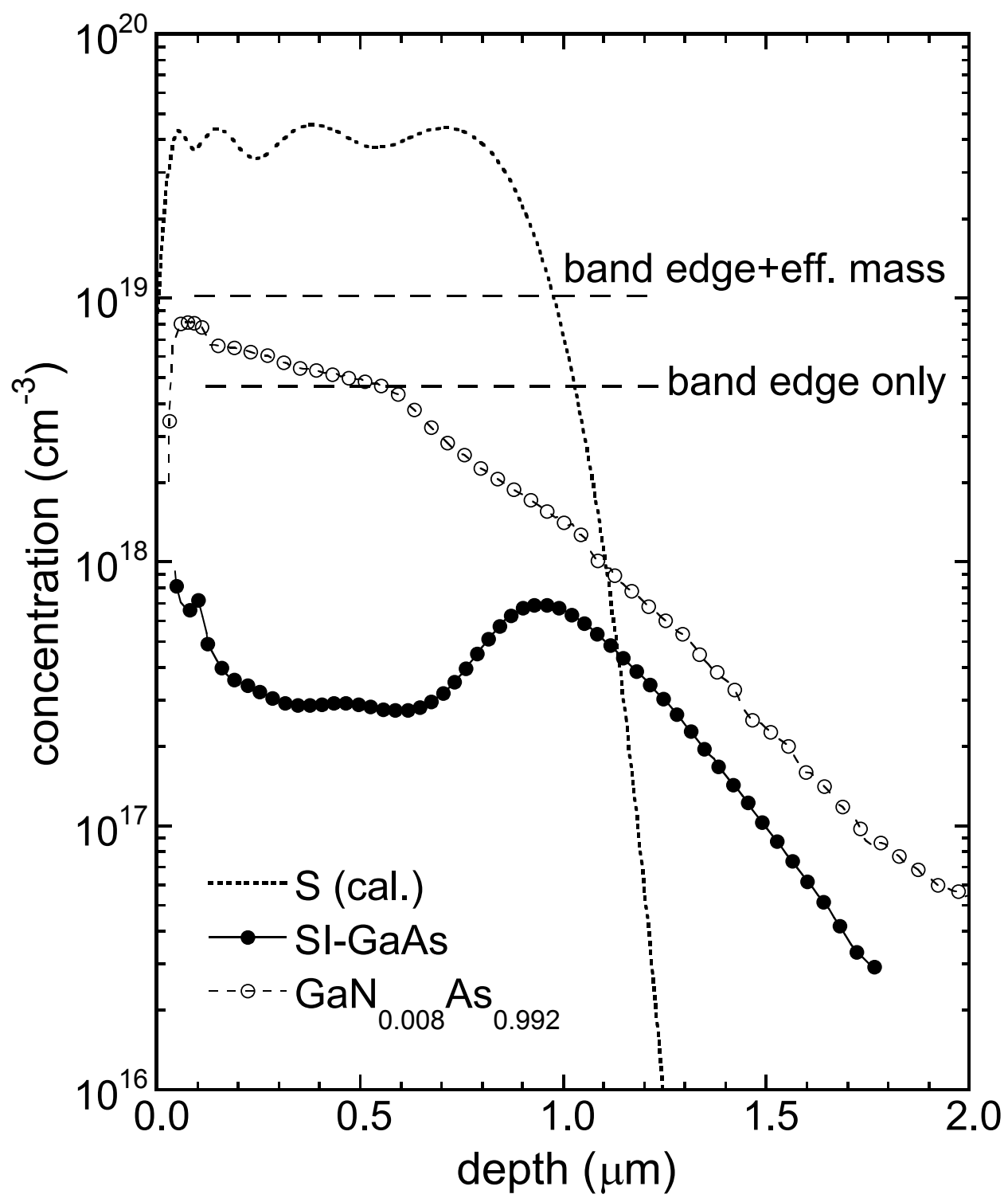

Figure 7 


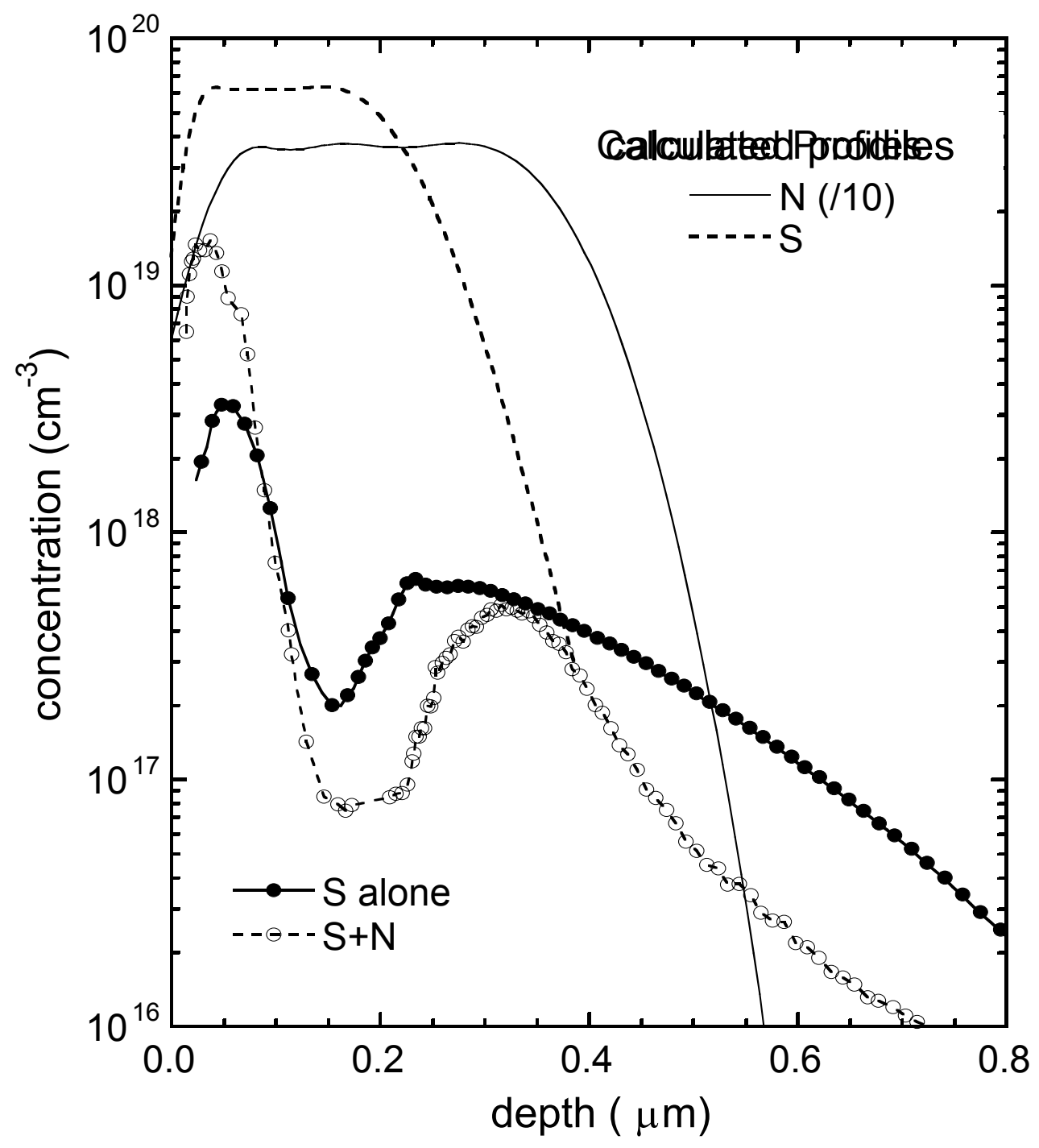

Figure 8 


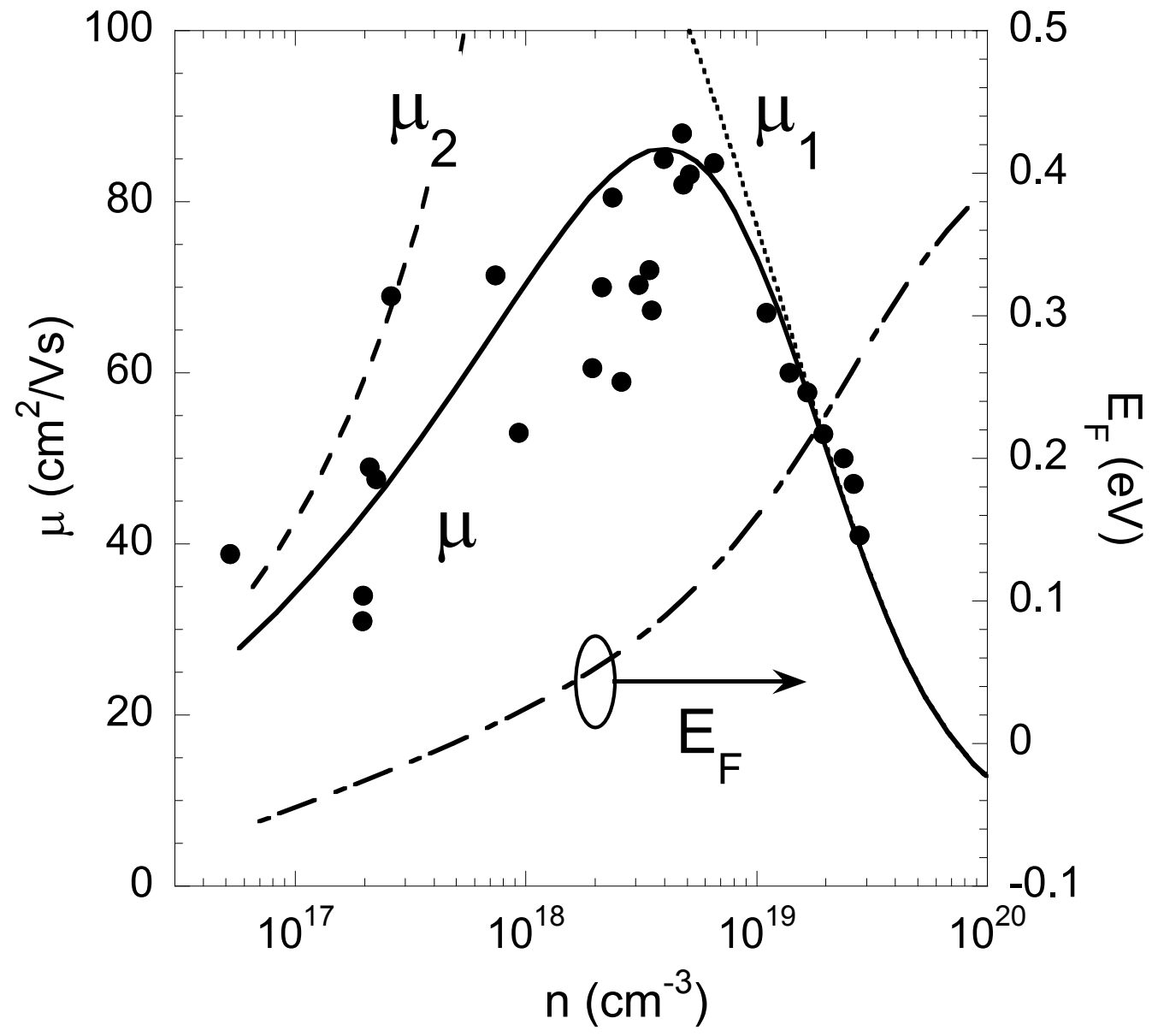

Figure 9 


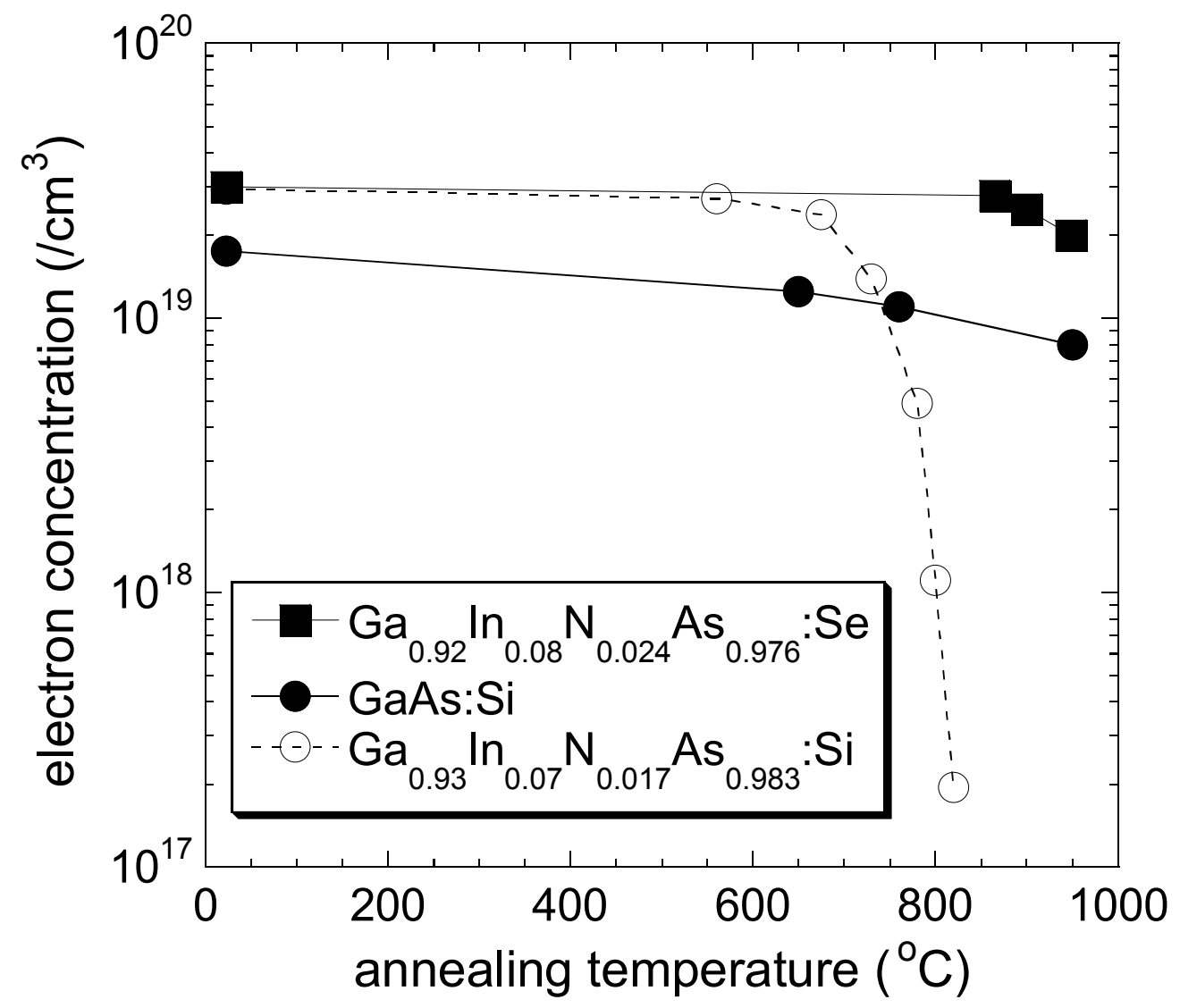

Figure 10 


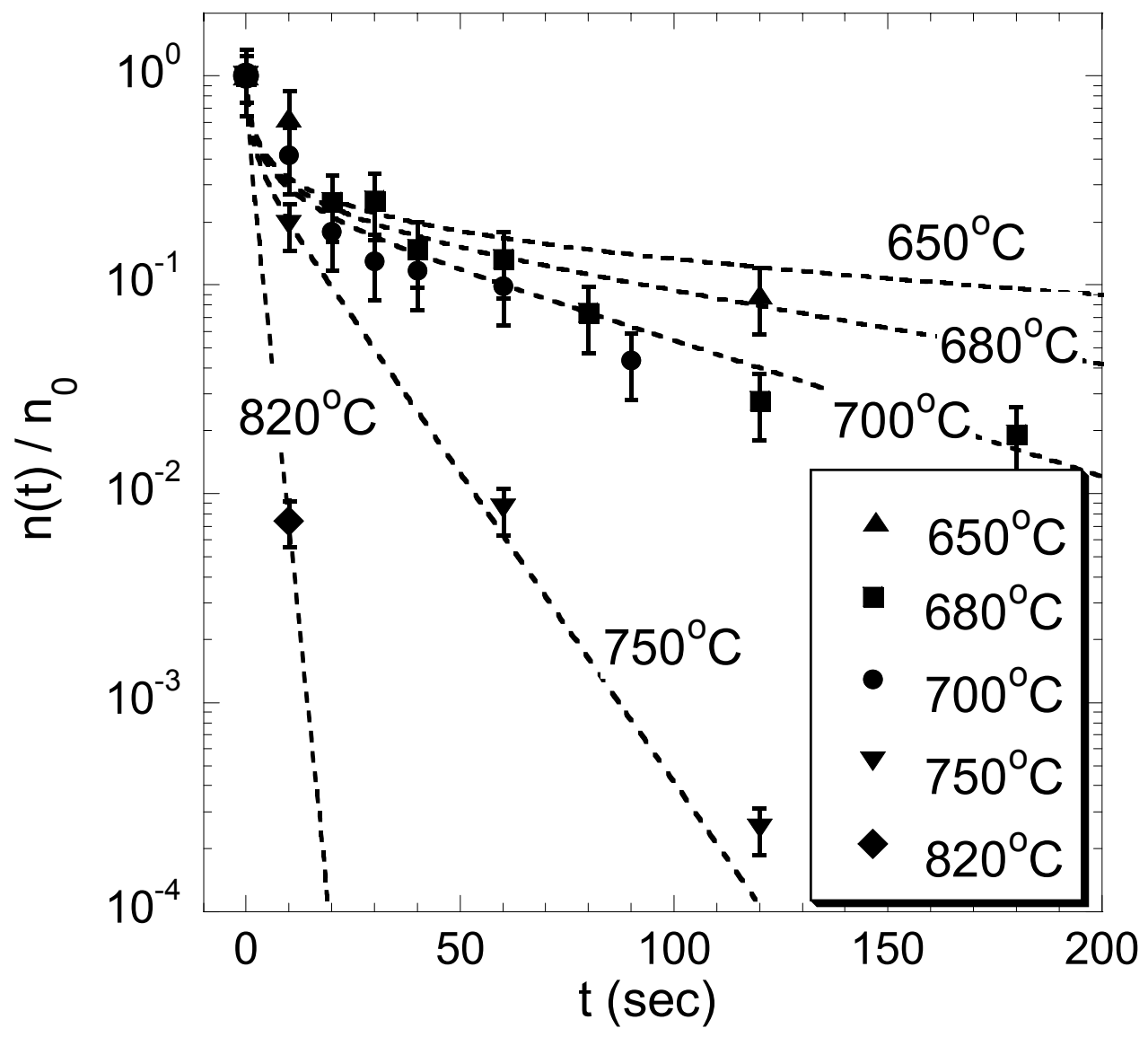

Figure 11 


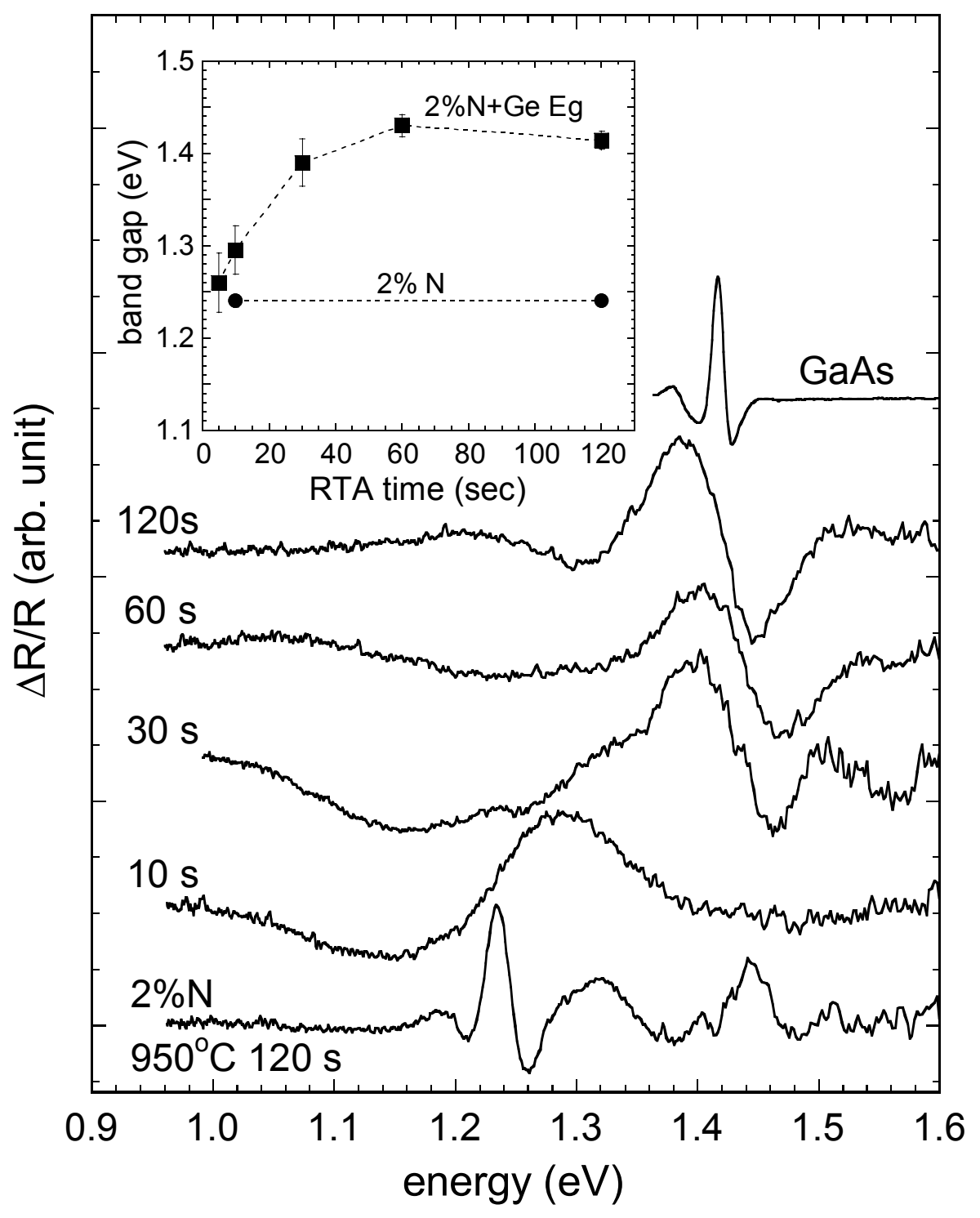

Figure 12 


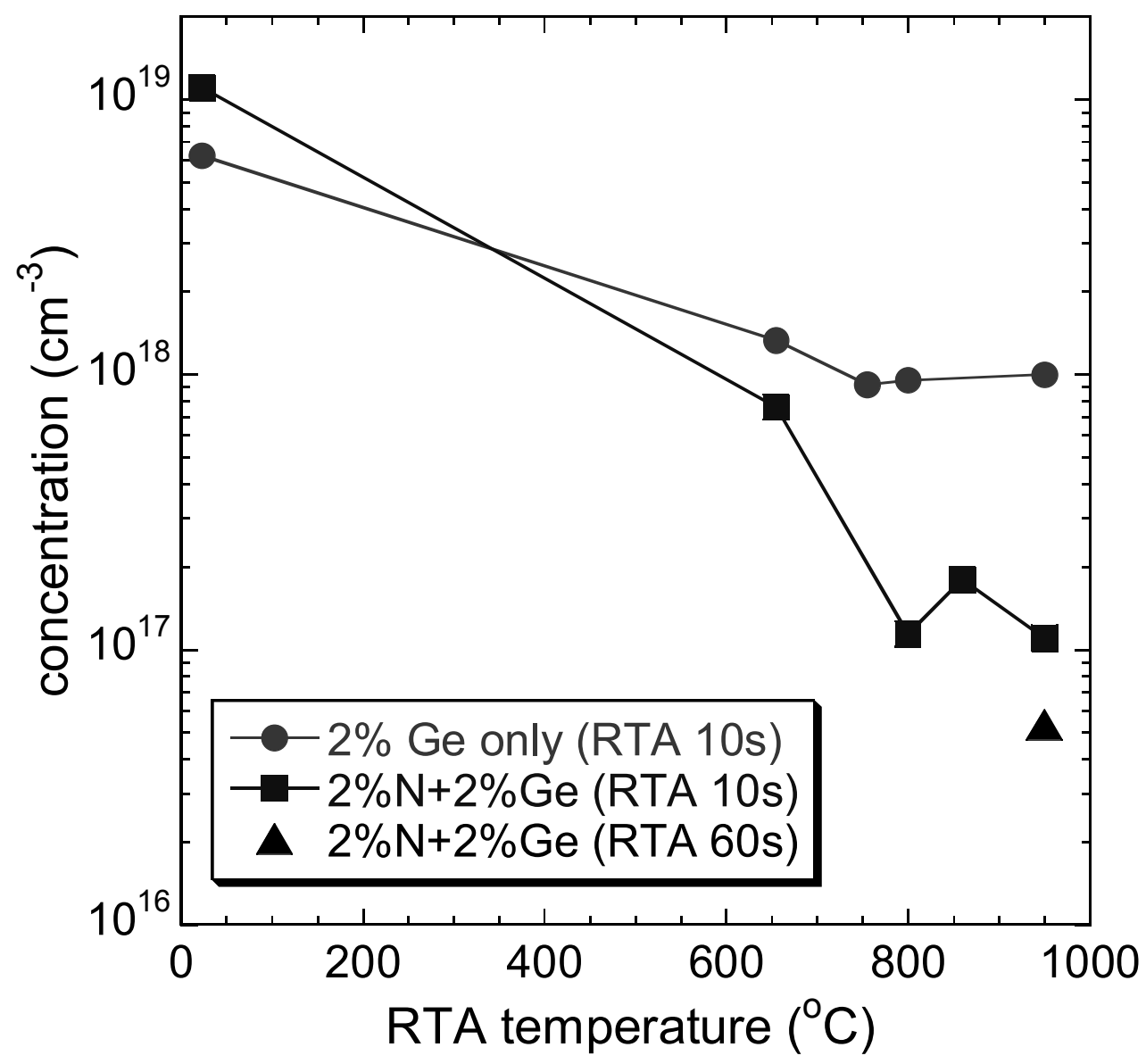

Figure 13 